\title{
Stepwise Determination of Multicompartment Disposition and Absorption Parameters from Extravascular Concentration-Time Data. Application to Mesoridazine, Flurbiprofen, Flunarizine, Labetalol, and Diazepam
}

\author{
John G. Wagner, ${ }^{1,2,7}$ Derek A. Ganes, ${ }^{1,6}$ Kamal K. Midha, ${ }^{3}$ \\ Iraida Gonzalez-Younes, ${ }^{1}$ J. Chris Sackellares, ${ }^{4}$ Larry D. Olson, \\ Melton B. Affrime, ${ }^{5}$ and James E. Patrick ${ }^{5}$
}

Received February 21, 1990 - Final May 23, 1991

When disposition is monoexponential, extravascular concentration-time $(\mathrm{C}, \mathrm{t})$ data yield both disposition and absorption parameters, the latter via the Wagner-Nelson method or deconvolution which are equivalent. Classically, when disposition is multiexponential, disposition parameters are obtained from intravenous administration and absorption data are obtained from extravascular $\mathrm{C}, \mathrm{t}$ data via the Loo-Riegelman or Exact Loo-Riegelman methods or via deconvolution. Thus, in multiexponential disposition one assumes no intrasubject variation in disposition, a hypothesis that has not been proven for most drugs. Based on the classical two-and three-compartment open models with central compartment elimination, and using postabsorptive extravascular $\mathrm{C}, \mathrm{t}$ data only, we have developed four equations to estimate $\mathrm{k}_{10}$ when disposition is biexponential and two other equations to estimate $\mathrm{k}_{10}$ when disposition is triexponential. The other disposition rate constants are readily obtained without intravenous data. We have analyzed extravascular data of furbiprofen (12 sets), mesoridazine (20 sets), flunarizine (5 sets), labetalol ( 9 sets), and

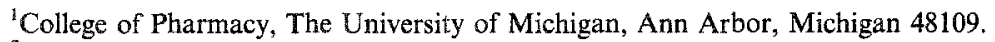

${ }^{2}$ Department of Pharmacology and Upjohn Center for Clinical Pharmacology, Medical School, The University of Michigan, Ann Arbor, Michigan 48109.

${ }^{3}$ College of Pharmacy, University of Saskatchewan, Saskatoon, Saskatchewan, Canada.

${ }^{4}$ Department of Neurology, Medical School, The University of Michigan, Ann Arbor, Michigan 48109.

${ }^{5}$ Schering Corporation, Galloping Hill Road, Kenilworth, New Jersey 07033.

'Present address: American Cyanamid Company, Medical Research Division, Middletown Road, Pearl River, New York 10965.

${ }^{7}$ To whom correspondence should be addressed at 2142 Spruceway Lane, Ann Arbor, Michigan 48103. 
diazepam (4 sets). In the case of diazepam intravenous $\mathrm{C}, \mathrm{t}$ data were also available for analysis. After disposition parameters had been estimated from the extravascular data the Exact LooRiegelman method with the Proost modification was applied to the absorptive extravascular data to obtain $\mathrm{A}_{T} / \mathrm{V}_{p}$ as a function of time. These latter data for each subject and each drug studied were found to be fitted by a function indicating either simple first-order absorption, two consecutive first-order processes, or zero-order absorption. After absorption and disposition parameters had been estimated, for each set of extravascular data analyzed, a reconstruction trend line through the original $\mathrm{C}, \mathrm{t}$ data was made. The new methods allow testing of the hypothesis of constancy of disposition with any given drug. There is also a need for new methods of analysis since the majority of drugs have no marketed intravenous formulation, hence the classical methods cannot be applied.

KEY WORDS: compartment models; disposition; absorption; mesoridazine; flurbiprofen; flunarizine; labetalol; diazepam.

\section{INTRODUCTION}

Compartment analysis has been and still is the most common approach to pharmacokinetic characterization of a drug in the body (1-3). Usually such a system of compartments has no anatomic or physiological reality. For those compartments involved in disposition of the drug the rates of transfer between compartments is assumed to obey first-order kinetics if the system is linear. It is not necessary to assume first-order kinetics for transfer of drug from an extravascular absorption site to the systemic circulation.

The purposes of pharmacokinetics are (i) to reduce data to meaningful numbers or parameters, (ii) to use the reduced data to make predictions of results of future experiments or predictions of results of a host of studies that would be too costly and time-consuming to be carried out (2), (iii) to allow quantitative correlation with pharmacodynamic effects, and (iv) to provide pharmaceutical scientists with quantitative methods to determine the effects of formulation factors on performance of dosage forms of drugs in animals and human beings.

To perform item (iv) above one usually requires absorption plots, and, classically, these have been obtained by methods outlined below. When disposition is monoexponential one estimates the first-order elimination rate constant from postabsorptive concentration-time data and then applies the Wagner-Nelson method (4) to data in the absorptive phase to obtain values of $A_{\mathrm{T}} / V$ (amount of drug absorbed to time $\mathrm{T}$ divided by the volume of distribution) as a function of time. Frequently, but not always, these values can be fitted to one of the absorption functions listed below in order to estimate one or more absorption rate constants. As a result of intrasubject variation of the elimination rate constant $\left(\lambda_{1}\right)$ of many drugs it is our opinion that this disposition parameter should not be estimated from data derived from a different treatment than the data being analyzed for absorption.

Classically, when disposition is bi- or triexponential the drug has been administered intravenously first, then extravascularly second. There have 
been two approaches: (i) Compartment model disposition parameters have been derived from the intravenous data, then these used in application of either the Loo-Riegelman method (5) or the Exact Loo-Riegelman method (6), as modified by Proost (7), to obtain values of $A_{\mathrm{T}} / V_{\mathrm{p}}$ (amount of drug absorbed to time $T$ divided by the volume of the central compartment) as a function of time; or, (ii) deconvolution is applied (8-11) using both the intravenous and extravascular data. Again, the $A_{\mathrm{T}} / V_{\mathrm{p}}$ vs. time data may frequently be fitted to an absorption function similar to one of those listed below and one or more absorption rate constants estimated.

The methods described above, which use intravenous data to evaluate extravascular data, involve the assumption that there is constancy of disposition parameters of the drug. This constitutes an hypothesis and there is evidence with many drugs that this hypothesis has to be rejected (12-29). Some authors $(14,16)$ have reported areas under concentration-time curves $(A U C)$, while others have reported elimination half-lives $(12,14,17)$ following administration of multiple single doses and have calculated measures of intra- and intersubject variation. We believe that clearances, rather than $A U C$ s, and elimination rate constants, rather than half-lives, should be analyzed for intra- and intersubject variation. We have reevaluated those data and have added evaluations of similar data (12-29) using the method outlined in Table I, where the intrasubject coefficient of variation $(\mathrm{CV})$ has been estimated for each subject from the four oral clearances measured on Days 2, 8,16, and 21 ; the lowest, highest, and median $C V \mathrm{~s}$ are then obtained and are reported in Table II. The grand mean parameter value and the intersubject $C V$ is estimated from the subject means as indicated in Table I and these are also shown in Table II. The intrasubject variation in the pharmacokinetic parameters listed in Table II may be the result of intrasubject variation in distribution and/or elimination. The data in Table II indicate a wide range in intrasubject variabilities. The first two rows of Table II

Table I. Example of Method of Calculation of Intra- and Intersubject Coefficients of Variation: Oral Clearance of Verapamil ${ }^{a}$

\begin{tabular}{ccccccc}
\hline & \multicolumn{3}{c}{ Oral clearance of verapamil (L/min) } & Subject & Intrasubject \\
\cline { 2 - 5 } Subject & Day 2 & Day 8 & Day 16 & Day 21 & $\bar{X}$ & \multicolumn{1}{c}{ CV $(\%)$} \\
\hline 1 & 2.53 & 2.42 & 3.01 & 2.31 & 2.57 & 12.0 Lowest \\
2 & 5.22 & 4.06 & 4.69 & 10.43 & 6.10 & 48.0 Highest \\
3 & 3.71 & 4.51 & 2.72 & 3.15 & 3.52 & 22.0 \\
4 & 2.09 & 2.38 & 2.57 & 1.74 & 2.20 & 16.5 Median \\
5 & 4.17 & 3.76 & 3.14 & 3.18 & 3.56 & 13.9 \\
Grand $\tilde{X}$ & & & & & 3.59 &
\end{tabular}

Intersubject $C V(\%)=42.4$

${ }^{a}$ Data from ref. 15 . 


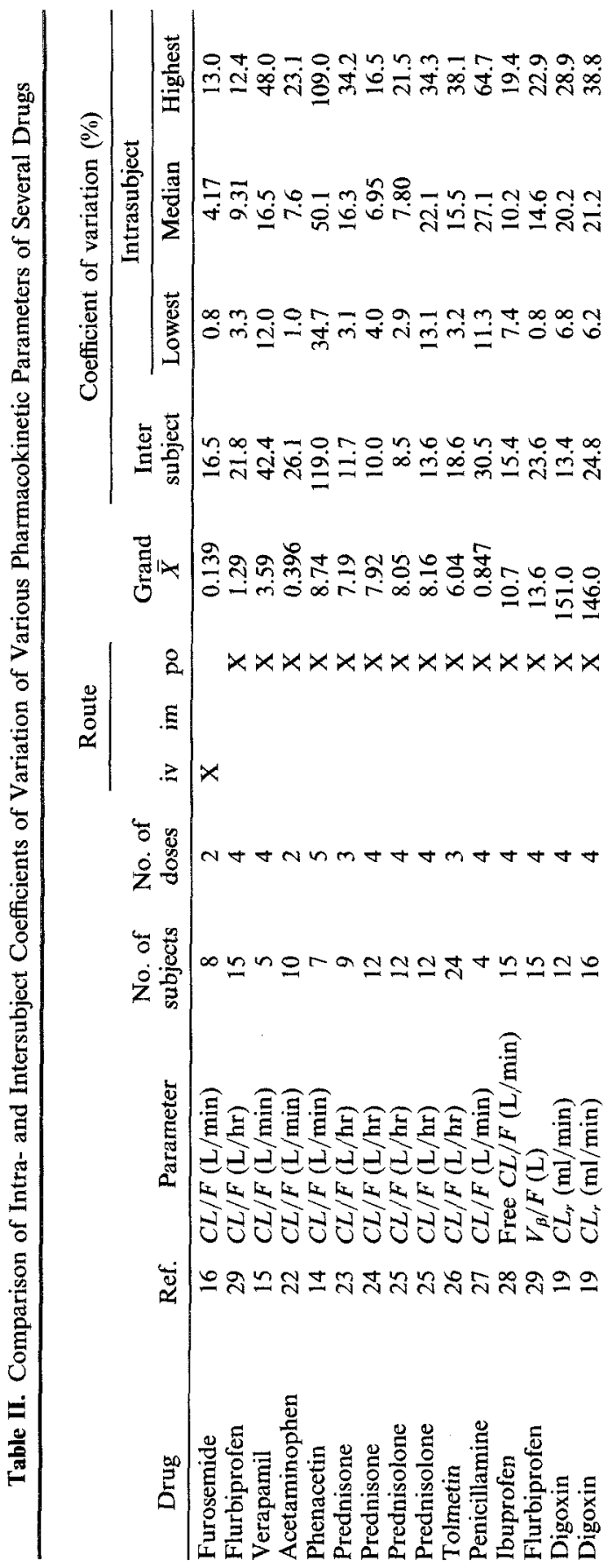




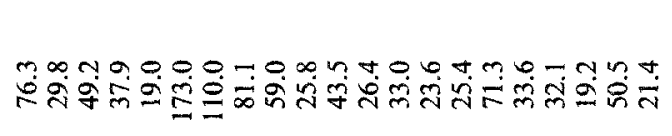

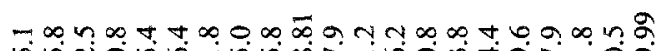

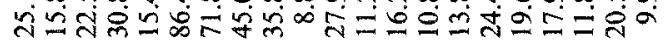

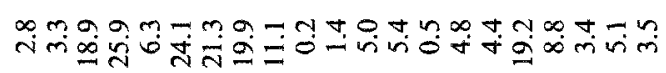

ron बें

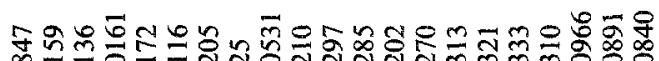

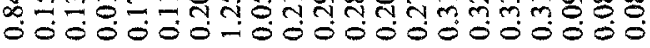

$\times \quad \times x \times x \times x \times x \times x \times x \times x \times x$

$x \times$

$x$

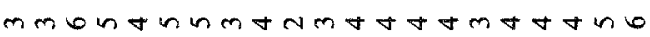

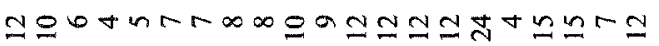

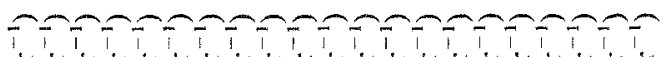

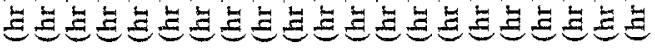

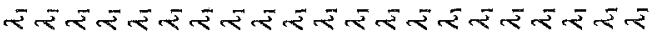

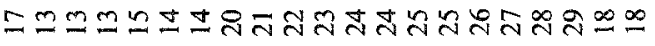

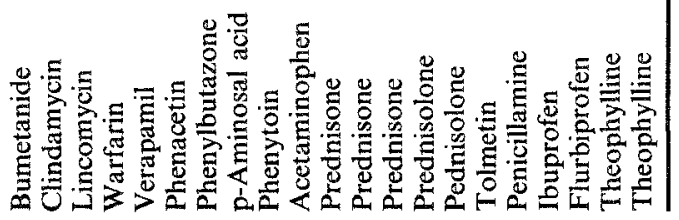


show that the systemic clearance of furosemide and the oral clearance of flurbiprofen have median and highest intrasubject $C V \mathrm{~s}$ which are lower than the intersubject $C V$ s. However, in the 22nd row one can see that for the $\lambda_{1}$ of phenylbutazone the median and highest intrasubject $C V \mathrm{~s}$ of 71.8 and $110 \%$, respectively, are considerably higher than the intersubject $C V$ of $35.6 \%$. In 19 of the 36 examples in Table II the median intrasubject $C V$ is greater than the intersubject $C V$.

Here we develop several methods to estimate disposition parameters of the classical two- and three-compartment disposition models from postabsorptive extravascular (oral, im, subcutaneous, etc.) data without the need for intravenous data.

The purposes of this article are (i) to describe the new methods to estimate classical two- and three-compartment disposition parameters from postabsorptive plasma (serum or whole blood) concentration-time data; (ii) to illustrate application of these methods to extravascular data of flurbiprofen, mesoridazine, flunarizine, labetalol, and diazepam, and present results of these pharmacokinetic analysis; (iii) to illustrate application of the Exact Loo-Riegelman method (6) with the Proost modification (7) to concentration-time data in the absorptive phase of the same data sets and present results of fitting $A_{\mathrm{T}} / V_{\mathrm{p}}$ or fraction absorbed values to obtain the kinetics of absorption; and (iv) to show how results from (ii) and (iii) may be combined to allow reconstruction of the original concentration-time data.

\section{EXPERIMENTAL}

\section{Format}

Method 1 is the classical one where intravenous data are fitted with a bi- or triexponential equation and disposition rate constants are estimated from the coefficients and exponents of such equations by methods previously described $(2,3)$.

In the Equations section below, equations needed to apply Methods 2, 3,4 , and 5 are given. The two-compartment open model and biexponential disposition is considered first, followed by the three-compartment open model and triexponential disposition. A Source of Equations section follows and the origins of the equations in the Equations section are given. These sections are followed by a section giving details of Applications of the Equations to extravascular data of specific drugs.

Methods 3 and 5 involve direct computer fitting of postabsorptive concentration-time data. If one uses the microcomputer program MINSQ (30) and the SIMPLEX method is initially used then no initial estimates of the parameters are required. Nonlinear least squares should always be the final 
method used. Methods 2 and 4 are most suited for cases where there has been zero-order input over a time $\tau$ and hence the mean input time, $M I T$, is known, namely $\tau / 2$.

\section{Equations}

The classical two-compartment open model is shown in Scheme 1.

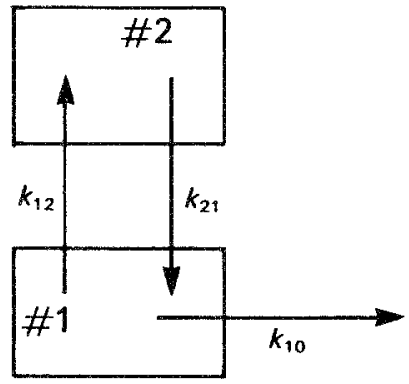

Scheme 1. The two-compartment open model.

For Methods 2, 3, 4, and 5 postabsorptive concentration-time data are initially computer-fitted to Eq. (1)

$$
C=B_{1} e^{-\lambda_{1} t}+B_{2} e^{-\lambda_{2} t} \quad\left(\lambda_{1}<\lambda_{2}\right)
$$

Method 2

$$
\begin{aligned}
& k_{10}=\lambda_{1}+\lambda_{2}-\lambda_{1} \lambda_{2}(M R T) \\
& k_{21}=\frac{\lambda_{1} \lambda_{2}}{k_{10}} \\
& k_{12}=\lambda_{1}+\lambda_{2}-k_{10}-k_{21}
\end{aligned}
$$

where $M R T=(A U M C / A U C)-M I T$ (see Glossary).

\section{Method $3 A$}

Postabsorptive concentration-time data are computer fitted to Eq. (5) using the $A U C$ from Eq. (6) and $\lambda_{1}$ and $\lambda_{2}$ from Eq. (1) as constants and 
$k_{10}$ and $t_{\mathrm{s}}$ as estimated parameters.

$$
\begin{gathered}
C=\frac{A U C}{\lambda_{2}-\lambda_{1}}\left[\lambda_{1}\left(\lambda_{2}-k_{10}\right) e^{-\lambda_{1}\left(t-t_{5}\right)}+\lambda_{2}\left(k_{10}-\lambda_{1}\right) e^{-\lambda_{2}\left(t-t_{5}\right)}\right] \\
A U C=\int_{0}^{T} C d t+\hat{C}_{\mathrm{T}} / \lambda_{1}
\end{gathered}
$$

The $C_{\mathrm{T}}$ of Eq. (6) is given by Eq. (7), where $T$ is the last sampling time.

$$
\hat{C}_{\mathrm{T}}=B_{1} e^{-\lambda_{1} T}+B_{2} e^{-\lambda_{2} T}
$$

\section{Method 3B}

Postabsorptive concentration-time data are computer fitted to Eq. (5) with $\lambda_{1}, \lambda_{2}, k_{10}$ and $t_{\mathrm{s}}$ as estimated parameters, again using $A U C$ from Eqs. (6) and (7) as a constant.

\section{Method 4}

This method assumes that the dose is absorbed at a zero-order rate over time $\tau$; postabsorptive concentration-time data are treated like postinfusion data and $\tau$ is the time shift required to do this.

$$
k_{10}=\lambda_{2}-\frac{\left(\lambda_{2}-\lambda_{1}\right)(\tau)\left(B_{1}\right)}{(A U C)\left(e^{+\lambda_{1} \tau}-1\right)}
$$

\section{Method 5}

This method makes the same assumption as in Method 4. Postabsorptive concentration-time data are computer fitted to Eq. (9) with $\lambda_{1}, \lambda_{2}$, and $A U C$ as constants and $k_{10}$ and $\tau$ as estimated parameters. Note that $\lambda_{1}$ and $\lambda_{2}$ are obtained in the initial fitting to Eq. (1).

$$
C=\frac{A U C\left(\lambda_{2}-k_{10}\right)\left(e^{+\lambda_{1} \tau}-1\right)}{\left(\lambda_{2}-\lambda_{1}\right) \tau} e^{-\lambda_{1} t}+\frac{A U C\left(k_{10}-\lambda_{1}\right)\left(e^{+\lambda_{2} \tau}-1\right)}{\left(\lambda_{2}-\lambda_{1}\right) \tau} e^{-\lambda_{2} t}
$$

In Methods 3A, 3B, 4, and 5 once $k_{10}$ has been estimated then $k_{21}$ and $k_{12}$ are obtained from Eqs. (3) and (4) using $\lambda_{1}$ and $\lambda_{2}$ from the fit to Eq. (1).

The classical three-compartment open model is shown in Scheme 2.

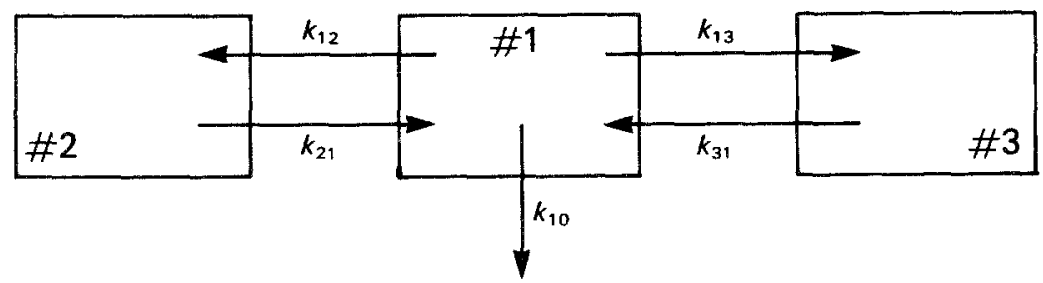

Scheme 2. The threc-compartment open model. 
For Methods 3A, 3B, and 5 postabsorptive concentration-time data are initially computer fitted to Eq. (10).

$$
C=B_{1} e^{-\lambda_{1} t}+B_{2} e^{-\lambda_{2} t}+B_{3} e^{-\lambda_{3} t}
$$

Method $3 \mathrm{~A}$

Postabsorptive concentration-time data are computer-fitted to Eq. (11) with $\lambda_{1}, \lambda_{2}$, and $\lambda_{3}$ from Eq. (10) and $A U C$ from Eqs. (6) and (7) as constants and $k_{10}, Z, t_{\mathrm{s}}$ as estimated parameters. $Z$ is the sum $k_{21}+k_{31}$.

$$
C=A U C\left[\begin{array}{c}
\frac{\left(k_{10}\left(\lambda_{1}^{2}-Z \lambda_{1}\right)+\lambda_{1} \lambda_{2} \lambda_{3}\right)}{\left(\lambda_{2}-\lambda_{1}\right)\left(\lambda_{3}-\lambda_{1}\right)} e^{-\lambda_{1}\left(t-t_{5}\right)} \\
+\frac{\left(k_{10}\left(\lambda_{2}^{2}-Z \lambda_{2}\right)+\lambda_{1} \lambda_{2} \lambda_{3}\right)}{\left(\lambda_{1}-\lambda_{2}\right)\left(\lambda_{3}-\lambda_{2}\right)} e^{-\lambda_{2}\left(t-t_{5}\right)} \\
+\frac{\left(k_{10}\left(\lambda_{3}^{2}-Z \lambda_{3}\right)+\lambda_{1} \lambda_{2} \lambda_{3}\right)}{\left(\lambda_{1}-\lambda_{3}\right)\left(\lambda_{2}-\lambda_{3}\right)} e^{-\lambda_{3}\left(t-t_{5}\right)}
\end{array}\right]
$$

\section{Method 3B}

Postabsorptive concentration-time data are computer-fitted to Eq. (11) with $A U C$ [from Eqs. (6) and (7)] as a constant and $\lambda_{1}, \lambda_{2}, \lambda_{3}, k_{10}, Z$, and $t_{\mathrm{s}}$ as estimated parameters.

\section{Method 5}

This method assumes that the dose is absorbed at zero-order rate over time $\tau$; postabsorptive concentration-time data are treated like postinfusion data and $\tau$ is the time shift required to do this. Postabsorptive concentrationtime data are computer-fitted to Eq. (12) with $\lambda_{1}, \lambda_{2}, \lambda_{3}$, and $A U C$ as constants and $k_{10}$, and $Z=k_{21}+k_{31}$ as estimated parameters.

$$
\begin{aligned}
C= & \frac{A U C\left(k_{10}\left(\lambda_{1}-Z\right)+\lambda_{2} \lambda_{3}\right)\left(e^{+\lambda_{1} \tau}-1\right)}{\left(\lambda_{2}-\lambda_{1}\right)\left(\lambda_{3}-\lambda_{1}\right) \tau} e^{-\lambda_{1} \tau} \\
& +\frac{A U C\left(k_{10}\left(\lambda_{2}-Z\right)+\lambda_{1} \lambda_{3}\right)\left(e^{+\lambda_{2} \tau}-1\right)}{\left(\lambda_{1}-\lambda_{2}\right)\left(\lambda_{3}-\lambda_{2}\right) \tau} e^{-\lambda_{2} t} \\
& +\frac{A U C\left(k_{10}\left(\lambda_{3}-Z\right)+\lambda_{1} \lambda_{2}\right)\left(e^{+\lambda_{3} \tau}-1\right)}{\left(\lambda_{1}-\lambda_{3}\right)\left(\lambda_{2}-\lambda_{3}\right) \tau} e^{-\lambda_{3} t}
\end{aligned}
$$

$A U M C / A U C$

$A U M C / A U C$ for the extravascular data is estimated directly from the 
data using Eq. (13) of Yamaoka et al. (31).

$$
\frac{A U M C}{A U C}=\frac{\int_{0}^{T} t C \cdot d t+\frac{\hat{C}_{\mathrm{T}} \cdot T}{\lambda_{1}}+\frac{\hat{C}_{\mathrm{T}}}{\lambda_{1}^{2}}}{A U C}
$$

In Eq. (13) $A U C$ is obtained with Eq. (6) and $\hat{C}_{\mathrm{T}}$ with Eq. (7). The integrals in Eq. (6) and in Eq. (13) were estimated with a combination of the linear and logarithmic rules using the criterion of Proost (7) to choose which rule to use at a specific place in the data set.

Methods 2 and 4 cannot be satisfactorily applied to the model of Scheme 2 after addition of extravascular input.

\section{Source of Equations}

Source of Eq. (2)

For the model of Scheme 1, Wagner (32) showed that Eq. (14) held.

$$
M R T=\frac{\lambda_{1}+\lambda_{2}-k_{10}}{\lambda_{1} \lambda_{2}}
$$

Rearrangement of Eq. (14) yields Eq. (2). The extravascular $A U M C$ / $A U C$ is the sum of two mean residence time functions as indicated by Eq. (15).

$$
A U M C / A U C=M R T+M I T
$$

Hence,

$$
M R T=A U M C / A U C-M I T
$$

Source of Eq. (5)

For the model of Scheme 1 and bolus intravenous administration the concentration, $C$, in compartment 1 is given by Eq. $(17)(2,3)$.

$$
C=\frac{C_{0}}{\lambda_{2}-\lambda_{1}}\left\{\left(k_{21}-\lambda_{1}\right) e^{-\lambda_{1} t}-\left(k_{21}-\lambda_{2}\right) e^{-\lambda_{2} t}\right\}
$$

Now

$$
C_{0}=k_{10} \cdot(A U C)
$$

Substituting for $C_{0}$ in Eq. (17) from Eq. (18) followed by use of Eq. (3) leads to Eq. (5). 
Source of Eq. (8)

For the model of Scheme 1 where there is zero-order input at the rate $k_{0}$ over time $\tau$ into compartment 1 the concentration, $C$, in compartment 1 when $t \geq \tau$ is given by Eq. (19) $(2,3)$.

$$
C=\frac{k_{0}\left(k_{21}-\lambda_{1}\right)\left(e^{+\lambda_{1} \tau}-1\right)}{\lambda_{1}\left(\lambda_{2}-\lambda_{1}\right) V_{\mathrm{p}}} e^{-\lambda_{1} t}+\frac{k_{0}\left(k_{21}-\lambda_{2}\right)\left(e^{+\lambda_{2} \tau}-1\right)}{\lambda_{2}\left(\lambda_{1}-\lambda_{2}\right) V_{\mathrm{p}}} e^{-\lambda_{2} t}
$$

If we apply Eq. (19) to extravascular data and let the coefficient of the $\lambda_{1}$ term be $B_{1}$ then $B_{1}$ is given by Eq. (20).

$$
B_{1}=\frac{k_{0}\left(k_{21}-\lambda_{1}\right)\left(e^{+\lambda_{1} \tau}-1\right)}{\lambda_{1}\left(\lambda_{2}-\lambda_{1}\right) V_{\mathrm{p}}}
$$

Now

$$
\frac{k_{0}}{V_{\mathrm{p}}}=\frac{D}{T V_{\mathrm{p}}}=\frac{C_{0}}{\tau}=\frac{k_{10}(A U C)}{\tau}
$$

Substituting for $k_{0} / V_{\mathrm{p}}$ in Eq. (20) from Eq. (21) gives

$$
B_{1}=\frac{k_{10}(A U C)\left(k_{21}-\lambda_{1}\right)\left(e^{+\lambda_{1} \tau}-1\right)}{\tau\left(\lambda_{2}-\lambda_{1}\right) V_{\mathrm{p}}}=\frac{(A U C)\left(\lambda_{2}-k_{10}\right)\left(e^{+\lambda_{1} \tau}-1\right)}{\tau\left(\lambda_{2}-\lambda_{1}\right)}
$$

hence

$$
\lambda_{2}-k_{10}=\frac{\left(\lambda_{2}-\lambda_{1}\right)(\tau)\left(B_{1}\right)}{(A U C)\left(e^{+\lambda_{1} \tau}-1\right)}
$$

Rearrangement of Eq. (23) gives Eq. (8).

Source of Eq. (11)

The concentration, $C$, in the central compartment of the model of Scheme 2 after bolus intravenous administration is given by Eq. (24) (3).

$$
\begin{aligned}
C= & C_{0}\left\{\frac{\left(k_{21}-\lambda_{1}\right)\left(k_{31}-\lambda_{1}\right)}{\left(\lambda_{2}-\lambda_{1}\right)\left(\lambda_{3}-\lambda_{1}\right)} e^{-\lambda_{1} t}+\frac{\left(k_{21}-\lambda_{2}\right)\left(k_{31}-\lambda_{2}\right)}{\left(\lambda_{1}-\lambda_{2}\right)\left(\lambda_{3}-\lambda_{2}\right)} e^{-\lambda_{2} t}\right. \\
& \left.+\frac{\left(k_{21}-\lambda_{3}\right)\left(k_{31}-\lambda_{3}\right)}{\left(\lambda_{1}-\lambda_{3}\right)\left(\lambda_{2}-\lambda_{3}\right)} e^{-\lambda_{3} t}\right\}
\end{aligned}
$$

Substituting for $C_{0}$ in Eq. (24) from Eq. (18), letting $Z=k_{21}+k_{31}$ be an estimated parameter and $t_{\mathrm{s}}$ be the time needed to shift the oral curve to the left to line up with the intravenous curve then the corresponding extravascular equation is Eq. (11). 
Source of Eq. (12)

The postinfusion equation where an infusion at the rate $k_{0}$ is put into compartment 1 over $\tau$ hours and time is measured from the start of the infusion is Eq. (25).

$$
\begin{aligned}
C= & \frac{k_{0}\left(k_{21}-\lambda_{1}\right)\left(k_{31}-\lambda_{1}\right)\left(e^{+\lambda_{1} \tau}-1\right)}{\lambda_{1}\left(\lambda_{2}-\lambda_{1}\right)\left(\lambda_{3}-\lambda_{1}\right) V_{\mathrm{p}} \tau} e^{-\lambda_{1} t} \\
& +\frac{k_{0}\left(k_{21}-\lambda_{2}\right)\left(k_{31}-\lambda_{2}\right)\left(e^{+\lambda_{2} \tau}-1\right)}{\lambda_{2}\left(\lambda_{1}-\lambda_{2}\right)\left(\lambda_{3}-\lambda_{2}\right) V_{\mathrm{p}} \tau} e^{-\lambda_{2} t} \\
& +\frac{k_{0}\left(k_{21}-\lambda_{3}\right)\left(k_{31}-\lambda_{3}\right)\left(e^{+\lambda_{3} \tau}-1\right)}{\lambda_{3}\left(\lambda_{1}-\lambda_{3}\right)\left(\lambda_{2}-\lambda_{3}\right) V_{\mathrm{p}} \tau} e^{-\lambda_{3} t}
\end{aligned}
$$

Substituting for $k_{0} / V_{\mathrm{p}}$ in Eq. (25) from Eq. (21), multiplying out the numerators of the three terms of Eq. (25), canceling the $\lambda_{1}$ in the numerator and denominator of the first term, then doing the same with $\lambda_{2}$ and $\lambda_{3}$ in the second and third terms, respectively, yields Eq. (12).

\section{Absorption Kinetics}

The Exact Loo-Riegelman method (6) with the Proost modifications (7) was applied to each set of extravascular data analyzed by Methods 2, 3, 4 , and 5 to obtain values of $A_{\mathrm{T}} / V_{\mathrm{p}}$ as a function of time. The asymptote, $A_{\infty} / V_{\mathrm{p}}$, of a plot of $A_{\mathrm{T}} / V_{\mathrm{p}}$ vs. time is theoretically equal to $C_{0}$ and, hence, as a result of Eq. (18) we obtain Eq. (26).

$$
\frac{A_{\infty}}{V_{\mathrm{p}}}=k_{10} \cdot(A U C)
$$

In some cases one might expect absorption to be irregular and not readily describable by a mathematical function. In such a case only the plot of $A_{\mathrm{T}} / V_{\mathrm{p}}$ vs. $t$ may be presented. However, in all cases where the new methods have been applied by us we have been able to fit the $A_{\mathrm{T}} / V_{\mathrm{p}}$ vs. $t$ data to one of Eqs. (28), (29), or (30) and the fraction absorbed, $F A$, vs. $t$ data to one of Eqs. (31), (32), or (33), where

$$
\begin{gathered}
F A=\frac{A_{\mathrm{T}} / V_{\mathrm{p}}}{A_{\infty} / V_{\mathrm{p}}}=\frac{A_{\mathrm{T}} / V_{\mathrm{p}}}{k_{10} \cdot(A U C)}=\frac{A_{\mathrm{T}}}{A_{\infty}} \\
A_{\mathrm{T}} / V_{\mathrm{p}}=\left(A_{\infty} / V_{\mathrm{p}}\right)\left\{1-e^{-k_{\mathrm{a}}\left(t-t_{0}\right)}\right\} \\
A_{\mathrm{T}} / V_{\mathrm{p}}=\left(A_{\infty} / V_{\mathrm{p}}\right)\left\{1-\frac{1}{k_{1}-k_{2}}\left(k_{1} e^{-k_{2} t}-k_{2} e^{-k_{1} t}\right)\right\}
\end{gathered}
$$




$$
\begin{gathered}
\frac{A_{\mathrm{T}}}{V_{\mathrm{p}}}=\left(\frac{k_{0}}{V_{\mathrm{p}}}\right)\left(t-t_{0}\right) \\
F A=1-e^{-k_{\mathrm{a}}\left(t-t_{0}\right)} \\
F A=1-\frac{1}{k_{1}-k_{2}}\left(k_{1} e^{-k_{2} t}-k_{2} e^{-k_{1} t}\right) \\
F A=\left(\frac{k_{0}}{A_{\infty}}\right)\left(t-t_{0}\right)
\end{gathered}
$$

It should be noted for Eq. (30) that when $t-t_{0}$ is equal to the time when the dose has been absorbed then $k_{0}\left(t-t_{0}\right)=A_{\infty}$; the same thing is true for Eq. (33) in which case $F A=1$ also. In Eqs. (28) and (29), $A_{\infty} / V_{\mathrm{p}}$ was usually equal to $k_{10}(A U C)$.

Equations (28) and (31) are for simple first-order absorption with a lag time, $t_{0}$; Eqs. (29) and (32) are for two consecutive first-order processes without a lag time, where, for example, $k_{1}$ could refer to dissolution and stomach emptying and $k_{2}$ refer to absorption across the gastrointestinal barrier, or vice versa, in the case of oral administration. Eqs. (30) and (33) are for zero-order absorption; note that when $A_{\mathrm{T}} / V_{\mathrm{p}}$ is plotted vs. $t-t_{0}$ the slope of the least squares line is $k_{0} / V_{\mathrm{p}}$ and when $F A$ is plotted against $t-t_{0}$ the slope of least square line is $k_{0} / A_{\infty}$.

\section{Reconstructions}

In this article on system analysis Veng Pedersen (33) stated: "Unfortunately, it is sometimes difficult and even impossible to reconstruct the basic drug level response from the parameters presented in pharmacokinetic studies." In the course of this research we have determined absorption and disposition parameters from 50 sets of extravascular concentration-time data and have successfully made reconstructions using the parameters estimated by each of the methods. In each case such a reconstruction is a theoretical trend line drawn through a plot of the original concentrationtime data and based on the complete compartment model elaborated by the stepwise procedure and the parameters which were estimated. The compartment models which were elaborated and the equations used in the reconstructions are shown below.

\section{Mesoridazine (20 Sets) and Flurbiprofen (12 Sets)}

The compartment model elaborated is shown as Scheme 3 and the 


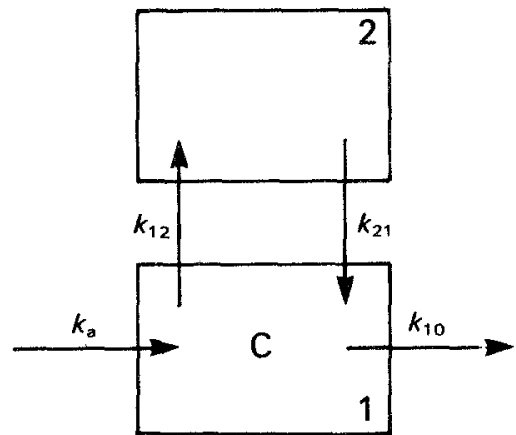

Scheme 3. Model elaborated stepwise for both mesoridazine besylate and sodium flurbiprofen solution orally.

reconstruction equation as Eq. (34).

$C=k_{\mathrm{a}} C_{0}\left[\frac{\left(k_{21}-\lambda_{1}\right) e^{-\lambda_{1}\left(t-t_{0}\right)}}{\left(\lambda_{2}-\lambda_{1}\right)\left(k_{\mathrm{a}}-\lambda_{1}\right)}+\frac{\left(k_{21}-\lambda_{2}\right) e^{-\lambda_{2}\left(t-t_{0}\right)}}{\left(\lambda_{1}-\lambda_{2}\right)\left(k_{\mathrm{a}}-\lambda_{2}\right)}+\frac{\left(k_{21}-k_{\mathrm{a}}\right) e^{-k_{\mathrm{a}}\left(t-t_{0}\right)}}{\left(k_{\mathrm{a}}-\lambda_{1}\right)\left(k_{\mathrm{a}}-\lambda_{2}\right)}\right]$

\section{Flunarizine (5Sets)}

The compartment model elaborated is shown as Scheme 4 and the reconstruction equation as Eq. (35) which was used for data for four patients showing first-order absorption and as Eqs. (36) and (37) which were used with one patient where the first-order input rate constant of Scheme 4 was

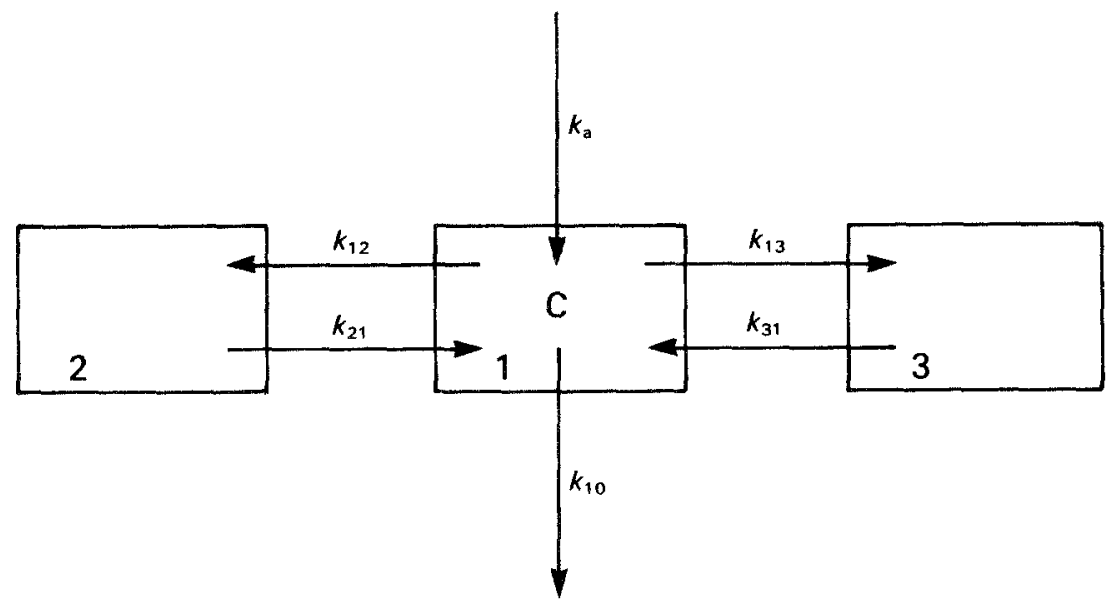

Scheme 4. Model elaborated stepwise for flunarizine administered orally. 
changed to a zero-order rate constant, $k_{0}$.

$$
\begin{aligned}
C=k_{\mathrm{a}} C_{0}\left[\frac{\left(k_{21}-\lambda_{1}\right)\left(k_{31}-\lambda_{1}\right) e^{-\lambda_{1}\left(t-t_{0}\right)}}{\left(\lambda_{2}-\lambda_{1}\right)\left(\lambda_{3}-\lambda_{1}\right)\left(k_{\mathrm{a}}-\lambda_{1}\right)}+\frac{\left(k_{21}-\lambda_{2}\right)\left(k_{31}-\lambda_{2}\right) e^{-\lambda_{2}\left(t-t_{0}\right)}}{\left(\lambda_{1}-\lambda_{2}\right)\left(\lambda_{3}-\lambda_{2}\right)\left(k_{\mathrm{a}}-\lambda_{2}\right)}\right. \\
\left.+\frac{\left(k_{21}-\lambda_{3}\right)\left(k_{31}-\lambda_{3}\right) e^{-\lambda_{3}\left(t-t_{0}\right)}}{\left(\lambda_{1}-\lambda_{3}\right)\left(\lambda_{2}-\lambda_{3}\right)\left(k_{\mathrm{a}}-\lambda_{3}\right)}+\frac{\left(k_{21}-k_{\mathrm{a}}\right)\left(k_{31}-k_{\mathrm{a}}\right) e^{-k_{\mathrm{a}}\left(t-t_{0}\right)}}{\left(\lambda_{1}-k_{\mathrm{a}}\right)\left(\lambda_{2}-k_{\mathrm{a}}\right)\left(\lambda_{3}-k_{\mathrm{a}}\right)}\right]
\end{aligned}
$$

During zero-order absorption

$$
C=\frac{k_{0}}{V_{\mathrm{p}}}\left[\begin{array}{c}
\left.\frac{\left(k_{21}-\lambda_{1}\right)\left(k_{31}-\lambda_{1}\right)}{\lambda_{1}\left(\lambda_{2}-\lambda_{1}\right)\left(\lambda_{3}-\lambda_{1}\right)}\left(e^{+\lambda_{1}\left(t-t_{0}\right)}-1\right) e^{-\lambda_{1}(t-0)}\right) \\
\left.+\frac{\left(k_{21}-\lambda_{2}\right)\left(k_{31}-\lambda_{2}\right)}{\lambda_{2}\left(\lambda_{1}-\lambda_{2}\right)\left(\lambda_{3}-\lambda_{2}\right)}\left(e^{+\lambda_{2}\left(t-t_{0}\right)}-1\right) e^{-\lambda_{2}\left(t-t_{0}\right)}\right) \\
\left.+\frac{\left(k_{21}-\lambda_{3}\right)\left(k_{31}-\lambda_{3}\right)}{\lambda_{3}\left(\lambda_{1}-\lambda_{3}\right)\left(\lambda_{2}-\lambda_{3}\right)}\left(e^{+\lambda_{3}\left(t-t_{0}\right)}-1\right) e^{-\lambda_{3}\left(t-t_{0}\right)}\right)
\end{array}\right]
$$

After zero-order absorption

$$
C=\frac{k_{0}}{V_{\mathrm{p}}}\left[\begin{array}{c}
\frac{\left(k_{21}-\lambda_{1}\right)\left(k_{31}-\lambda_{1}\right)}{\lambda_{1}\left(\lambda_{2}-\lambda_{1}\right)\left(\lambda_{3}-\lambda_{1}\right)}\left(e^{+\lambda_{3}\left(\tau-t_{0}\right)}-1\right) e^{-\lambda_{1}\left(t-t_{0}\right)} \\
+\frac{\left(k_{21}-\lambda_{2}\right)\left(k_{31}-\lambda_{2}\right)}{\lambda_{2}\left(\lambda_{1}-\lambda_{2}\right)\left(\lambda_{3}-\lambda_{2}\right)}\left(e^{+\lambda_{2}\left(\tau-t_{0}\right)}-1\right) e^{-\lambda_{2}\left(t-t_{0}\right)} \\
+\frac{\left(k_{21}-\lambda_{3}\right)\left(k_{31}-\lambda_{3}\right)}{\lambda_{3}\left(\lambda_{1}-\lambda_{3}\right)\left(\lambda_{2}-\lambda_{3}\right)}\left(e^{+\lambda_{3}\left(\tau-t_{0}\right)}-1\right) e^{-\lambda_{3}\left(t-t_{0}\right)}
\end{array}\right]
$$

Labetalol (9 Sets)

The compartment model elaborated is shown as Scheme 5 and the reconstruction equations as Eqs. (38) and (39)

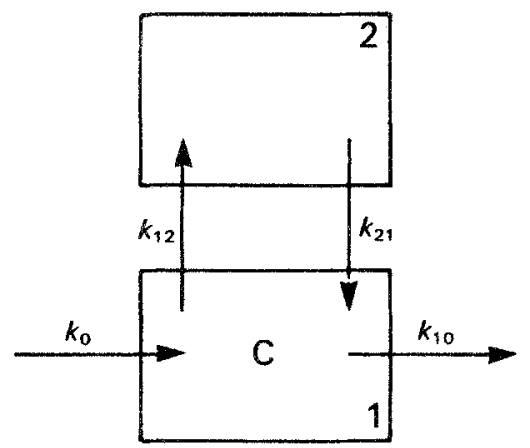

Scheme 5. Model elaborated stepwise for labetolol administered in solution via intestinal infusion. 
During zero-order input

$$
C=\frac{k_{0}\left(k_{21}-\lambda_{1}\right)\left(e^{+\lambda_{1} t}-1\right) e^{-\lambda_{1} t}}{\lambda_{1}\left(\lambda_{2}-\lambda_{1}\right) V_{\mathrm{p}}}+\frac{k_{0}\left(k_{21}-\lambda_{2}\right)\left(e^{+\lambda_{2} t}-1\right) e^{-\lambda_{2} t}}{\lambda_{2}\left(\lambda_{2}-\lambda_{1}\right) V_{\mathrm{p}}}
$$

After zero-order input ceases at $t=\tau$

$$
C=\frac{k_{0}\left(k_{21}-\lambda_{1}\right)\left(e^{+\lambda_{1} \tau}-1\right) e^{-\lambda_{1} t}}{\lambda_{1}\left(\lambda_{2}-\lambda_{1}\right) V_{\mathrm{p}}}+\frac{k_{0}\left(k_{21}-\lambda_{2}\right)\left(e^{+\lambda_{2} \tau}-1\right) e^{-\lambda_{2} t}}{\lambda_{2}\left(\lambda_{2}-\lambda_{1}\right) V_{\mathrm{p}}}
$$

\section{Diazepam (4 Sets)}

The compartment model elaborated is shown as Scheme 6 and the reconstruction equation as Eq. (40).

$$
\begin{aligned}
C= & k_{1} k_{2} c_{0}\left\{\frac{\left(k_{21}-\lambda_{1}\right)\left(k_{31}-\lambda_{1}\right) e^{-\lambda_{1} t}}{\left(\lambda_{2}-\lambda_{1}\right)\left(k_{1}-\lambda_{1}\right)\left(k_{2}-\lambda_{1}\right)\left(\lambda_{3}-\lambda_{1}\right)}\right. \\
& +\frac{\left(k_{21}-\lambda_{2}\right)\left(k_{31}-\lambda_{2}\right) e^{-\lambda_{2} t}}{\left(\lambda_{1}-\lambda_{2}\right)\left(k_{1}-\lambda_{2}\right)\left(k_{2}-\lambda_{2}\right)\left(\lambda_{3}-\lambda_{2}\right)} \\
& +\frac{\left(k_{21}-\lambda_{3}\right)\left(k_{31}-\lambda_{3}\right) e^{-\lambda_{3} t}}{\left(\lambda_{1}-\lambda_{3}\right)\left(\lambda_{2}-\lambda_{3}\right)\left(k_{1}-\lambda_{3}\right)\left(k_{2}-\lambda_{3}\right)} \\
& +\frac{\left(k_{21}-k_{1}\right)\left(k_{31}-k_{1}\right) e^{-k_{1} t}}{\left(\lambda_{1}-k_{1}\right)\left(\lambda_{2}-k_{1}\right)\left(\lambda_{3}-k_{1}\right)\left(k_{2}-k_{1}\right)} \\
& \left.+\frac{\left(k_{21}-k_{2}\right)\left(k_{31}-k_{2}\right) e^{-k_{2} t}}{\left(\lambda_{1}-k_{2}\right)\left(\lambda_{2}-k_{2}\right)\left(\lambda_{3}-k_{2}\right)\left(k_{1}-k_{2}\right)}\right\}
\end{aligned}
$$

\section{Simulations}

Three sets of concentration-time data were generated with the model of Scheme 3 and Eq. (34). The parameter $t_{0}$ was made equal to zero in all cases. The three sets of data were derived using $k_{10}, k_{12}, k_{21}$, and $k_{\mathrm{a}}$ values very similar to those values which estimated from real flurbiprofen plasma concentrations measured following oral administration of a solution of the sodium salt of flurbiprofen and which were analyzed by the new methods (see Results section). We believe it is much more relevant to use parameter values in simulations similar to those estimated from real data than to use random numbers. For each data set 12 concentrations were generated corresponding to the times $0.1,0.25,0.5,1.5,2.5,4,6,8,12,16,24$, and $32 \mathrm{hr}$ which simulated what could be readily done experimentally. 


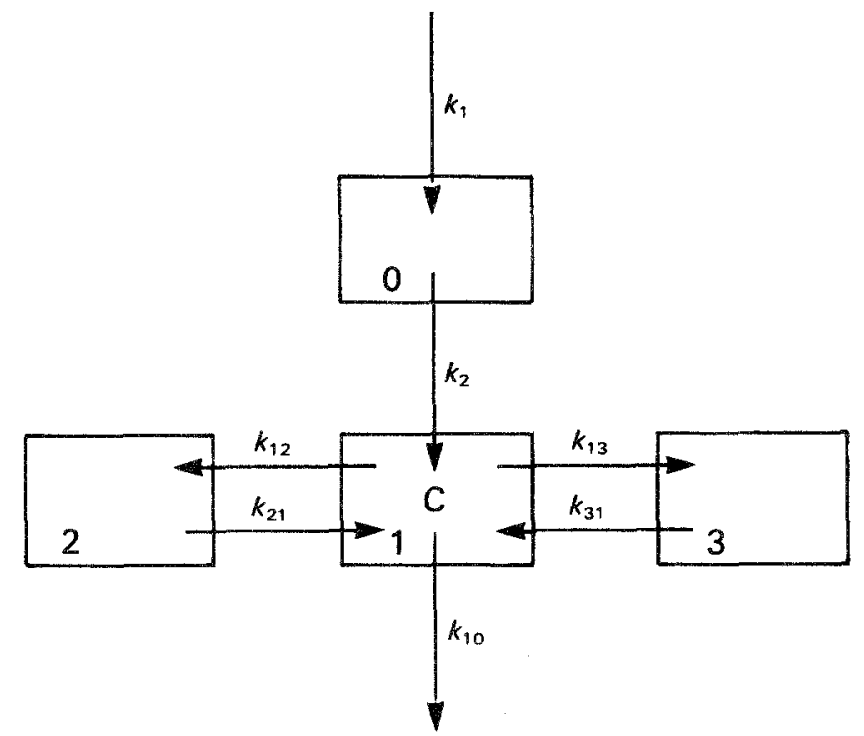

Scheme 6. Model elaborated stepwise for diazepam administered orally in immediate-release tablets.

\section{Analysis of Real Concentration-Time Data}

\section{Mesoridazine}

Data of Ganes (34) were used. Commercial tablets (Serenti1 ${ }^{\circledR}$, Sandoz) of $12.5,25$, and $50 \mathrm{mg}$ (free base), containing the drug as mesoridazine besylate, were administered to normal human beings as single doses at 2week intervals. Venous plasma samples were collected prior to drug administration and at $0.33,0.67,1,1.5,2,3,4,6,8,10,12,15,24,32,48$, and $72 \mathrm{hr}$ following administration of the highest dose; the 10 and $15 \mathrm{hr}$ samples were not collected following the two lowest doses. The unchanged drug was measured by a sensitive and specific HPLC method described in detail by Ganes (34).

Table III lists the times of the peak plasma concentrations (peak times) and the time of the first $C, t$ pair used in the biexponential fits to Eq. (1). These were very difficult data sets to decide what points to use first for the biexponential fits. If a point too near the peak was used then either a difference of two exponential terms or a triexponential equation fit the data; a later point was then used as the first point and another biexponential fit was attempted; the process was repeated until a biexponential equation with two positive coefficients fitted the data set well. The appearance of a plot of the data also helped the process. 
Table III. Peak Time and Time of First Data Point for Biexponential Fit to Equation (1) of Downslope $C, t$ Data for Mesoridazne Besylate

\begin{tabular}{|c|c|c|c|c|c|c|}
\hline \multicolumn{7}{|c|}{ Dose } \\
\hline \multirow[b]{2}{*}{ Subject } & \multicolumn{2}{|c|}{$12.5 \mathrm{mg}$} & \multicolumn{2}{|c|}{$25 \mathrm{mg}$} & \multicolumn{2}{|c|}{$50 \mathrm{mg}$} \\
\hline & $\begin{array}{l}\text { Peak time } \\
\text { (hr) }\end{array}$ & $\begin{array}{l}\text { First data } \\
\text { point (hr) }\end{array}$ & $\begin{array}{l}\text { Peak time } \\
\text { (hr) }\end{array}$ & $\begin{array}{l}\text { First data } \\
\text { point }(\mathrm{hr})\end{array}$ & $\begin{array}{l}\text { Peak time } \\
(\mathrm{hr})\end{array}$ & $\begin{array}{l}\text { First data } \\
\text { point }(\mathrm{hr})\end{array}$ \\
\hline 1 & 1.5 & 3 & 2 & 4 & 2 & 8 \\
\hline 2 & 1 & 4 & 0.67 & 4 & 1 & 10 \\
\hline 3 & - & - & - & - & 1.5 & 4 \\
\hline 4 & 0.67 & 3 & 1.5 & 4 & 4 & 8 \\
\hline 5 & 1 & 2 & - & - & 3 & 6 \\
\hline 7 & 1 & 4 & - & - & 1.5 & 8 \\
\hline 8 & - & - & 2 & 6 & 3 & 10 \\
\hline 11 & 3 & 6 & 1 & 4 & - & $\ldots$ \\
\hline 13 & - & - & 0.67 & 4 & 2 & 8 \\
\hline
\end{tabular}

The same data set with appropriate downslope starting time was then fitted to Eq. (5) in order to apply Method 3A and $k_{10}$ and $t_{\mathrm{s}}$ were estimated using Eq. (5); the $\lambda_{1}$ and $\lambda_{2}$ obtained in the biexponential fit to Eq. (1) were held constant when fitting to Eq. (5) was carried out. Values of $k_{21}$ and $k_{12}$ were then estimated with Eqs. (3) and (4). Using this set of $k_{12}, k_{21}$, and $k_{10}$ values the Exact Loo-Riegelman method (6) with the modification of Proost (7) was then applied to all of the $C, t$ data of the same data set; fraction absorbed values were then obtained with Eq. (27); these were fitted to Eq. (31) by nonlinear least squares with the program MINSQ (30) to estimate $k_{\mathrm{a}}$ and $t_{0}$ for Method $3 \mathrm{~A}$.

Method 2 was applied by obtaining $A U C$ with Eq. (6), $M R T$ with Eqs. (13) and (16) and using $M I T=1 / k_{\mathrm{a}}$, where $k_{\mathrm{a}}$ was obtained by application of Method 3A. A new $k_{10}$ was then obtained with Eq. (2) and the corresponding $k_{12}$ and $k_{21}$ values obtained with Eqs. (3) and (4) again.

Method 4 was applied by substituting into Eq. (8) using the first time for the biexponential fit as the value of $\tau$, the $A U C$ from Eq. (6), and $B_{1}$, $\lambda_{1}$, and $\lambda_{2}$ from the biexponential fit to Eq. (1).

Reconstructions were made using the model of Scheme 3, Eq. (34), and the constants estimated by Method 3A.

\section{Flurbiprofen}

Data of Gonzalez (35) was used. Twelve normal volunteers were each administered $25 \mathrm{ml}$ of a $2.5 \mathrm{mg} / \mathrm{ml}$ aqueous solution of sodium flurbiprofen followed by $6 \mathrm{oz}$. of water after an overnight fast and the subjects were fasted for $4 \mathrm{hr}$ postdose. Venous plasma samples were collected predose and at $0.083,0.167,0.25,0.33,0.5,0.75,1,2,4,6,8,12,24,30,36$, and $48 \mathrm{hr}$ postdose. Unchanged flurbiprofen was assayed by a specific and sensitive 
HPLC method with fluorescence detection described in detail by Szpunar (36).

It was less difficult with the flurbiprofen data than with the mesoridazine data to decide which $C, t$ pair should be the first data point for the biexponential fit to Eq. (1). For Subjects 1 and 4-12, the 2-hr point was the starting point and for Subjects 2 and 3, the 4-hr point was used. Analyses were carried out on the 12 sets of $C, t$ data as described above for the mesoridazine data.

Reconstructions were carried out using the model of Scheme 3, Eq. (34), and the constants obtained via Method 3A.

\section{Labetalol}

Two hundred milligrams of labetalol $\mathrm{HCl}$ in $40 \mathrm{ml}$ of solution was administered to each of nine normal volunteers as an intestinal infusion over a 4-hr period via a small bowel intubation tube. This study was performed under contract for Schering Corporation. The venous plasma concentrations of labetalol measured in this study are listed in Table A of the Appendix. Since $\tau=4$ in this case, $M I T=\tau / 2=2 \mathrm{hr}$ and Methods 2 and 4 are most appropriate to estimate disposition parameters and were the only methods employed. Eqs. (2), (3), (4), and (13) were used for Method 2 and Eqs. (3), (4), (8), and (13) were used for Method 4. Labetalol concentrations from 4-24 hr were used for the biexponential fittings to Eq. (1).

Reconstructions were carried out using the model of Scheme 5, Eqs. (38) and (39), and the parameters estimated by Method 2.

\section{Flunarizine}

Flunarizine pharmacokinetics were first described by Kapetanovic $e t$ al. (37). They administered $30 \mathrm{mg}$ single oral doses of flunarizine to 12 epileptic patients and drew plasma samples over a 32-day period. They fitted "postabsorptive" concentrations to a triexponential equation for each patient but did not specify which $C, t$ data points were used. They also reported values of the disposition parameters $k_{12}, k_{21}, k_{13}, k_{31}$, and $k_{10}$ for the classical threecompartment model (Scheme 2) but apparently did not correct for the fact the postabsorptive oral data were fitted to the triexponential equation rather than bolus iv data as required by the equations they apparently used.

In a study carried out by J. C. Sackellares in the Department of Neurology, The University of Michigan Medical School, five epileptic patients were administered single $30 \mathrm{mg}$ oral doses of flunarizine and venous plasma samples were collected for a 70-day period postdosing. The plasma samples were assayed for flunarizine by the Epilepsy Branch, National Institute of Neurological and Communicative Disorders and Stroke, Bethesda, MD. The plasma concentrations are listed in Table B of the Appendix. The 
first downslope data point taken for the triexponential fit to Eq. (10) was $7.9,6,6,6$, and $12 \mathrm{hr}$ for subjects M01LH, M07CL, M02SL, M03PS, and M05AL, respectively. The $C_{\mathrm{T}}$ value for each data set was obtained by substituting the time value indicated by the asterisk in Table B of the Appendix into Eq. (10) and the $A U C$ was obtained with Eq. (6).

Method 3A was applied by fitting postabsorptive data to Eq. (11) using the $\lambda_{1}$ s of Eq. (10) as constants and estimating $k_{10}, Z$ and $t_{\mathrm{s}}$. Equations of Gibaldi and Perrier (3) were used to obtain $k_{21}, k_{31}, k_{12}$, and $k_{13}$. The Exact Loo-Riegelman method (6) with the Proost modification (7) was then applied to all of the $C, t$ data of the same data set and fraction absorbed values were estimated with Eq. (27). The $F A, t$ data were computer-fitted to Eq. (31) to estimate $k_{\mathrm{a}}$ and $t_{0}$ for Method 3A.

Method 3B was applied using Eq. (11) and estimating $t_{\mathrm{s}}, k_{10}, Z, \lambda_{1}$, $\lambda_{2}$, and $\lambda_{3}$ by the method of least squares and the program MINSQ (30).

Method 5 was applied by fitting postabsorptive $C, t$ data to Eq. (12) with $\tau, Z$, and $k_{10}$ as estimated parameters. The remainder of the disposition rate constants were then estimated as described above for Method 3A.

The Exact Loo-Riegeman method (6) with the Proost modification (7) was then applied to all the $C, t$ data of each data set using the disposition parameters obtained by Methods $3 \mathrm{~A}$ and 5 then the $A_{\mathrm{T}} / V_{\mathrm{p}}$ data were treated as described above for Method 3A.

Reconstructions were performed using the model of Scheme 4, Eq. (35), and the constants obtained via Methods $3 \mathrm{~A}$ and 5.

\section{Diazepam}

Data used were those given in detail by Kaplan et al. (38). Four healthy male volunteers each received $10 \mathrm{mg}$ of diazepam by bolus iv injection and $10 \mathrm{mg}$ orally. Blood concentrations were measured at $1,2.5,5,10,15,20$, 30 , and 45 min and at $1,1.5,2,3,4,6,8,12,24,30$, and $48 \mathrm{hr}$ after iv dosing and at 15,30, and $45 \mathrm{~min}$ and at 1, 1.5, 2, 3, 4, 6, 8, 12, 24, 30, and $48 \mathrm{hr}$ after oral dosing. Although Kaplan et al. (38) reported coefficients and exponents of triexponential fits of the iv data, as well as $k_{12}, k_{21}, k_{13}, k_{31}$, and $k_{10}$ of the model of Scheme 2, we refit these data and found our fits had lower sums of squared deviations than those reported (38). The disposition parameters for Method 1 were estimated from the coefficients and exponents of the triexponential equation using the equations of Gibaldi and Perrier (3).

There were nine pairs of postabsorptive oral $C, t$ data in the 2- to 24-hr period for each subject and each set was computer-fitted to Eq. (10) using the program RSTRIP (30) with equal weights. Disposition parameters for the model of Scheme 2 were estimated by Methods $3 \mathrm{~A}$ and 5 by similar procedures as described above under flunarizine. Using the disposition 
parameters estimated by these methods the Exact Loo-Riegelman method (6) with the Proost modification (7) was applied to all of the $C, t$ data of each data set. $F A$ values were then obtained with Eq. (27) but attempted fittings of the $F A, t$ data to Eq. (32) gave "divide by zero" errors with the program MINSQ (30). Also, it was found that the asymptote of plots of $A_{\mathrm{T}} / V_{\mathrm{p}}$ vs. time was not equal to $k_{10}(A U C)$ for Methods 1 and $3 \mathrm{~A}$ but were for Method 5. The $A_{\mathrm{T}} / V_{\mathrm{p}}$ values were fitted to Eq. (29) with $A_{\infty} / V_{\mathrm{p}}, k_{1}$, and $k_{2}$ as estimated parameters. (40).

Reconstructions were performed with the model of Scheme 6 and Eq.

\section{RESULTS}

\section{Simulations}

Table IV gives results of application of Methods $3 \mathrm{~A}$ and 5 to the errorfree data generated as described under Simulations in the Experimental section. The Exact Loo-Riegelman method $(6,7)$ was applied to the $C, t$ data using the disposition parameters estimated by Methods $3 \mathrm{~A}$ and 5 . The $A_{\mathrm{T}} / V_{\mathrm{p}}$ data were fitted to Eq. (28) and the estimated $A_{\infty} / V_{\mathrm{p}}$ and $k_{\mathrm{a}}$ values are also listed in Table IV. Using Method $3 A$ the mean error in the parameter estimates was $1.28 \%$ and the mean absolute error was $3.0 \%$. Using Method 5 the mean error was $1.95 \%$ and the mean absolute error was $4.81 \%$. The largest errors were in the $k_{\mathrm{a}}$ estimates. The measures of fit, namely, $r^{2}$ and Model Selection Criterion ( $M S C$ ) were all very high in these fittings.

Figure 1 explains Method 3A and Fig. 2 explains Method 5. These figures are based on the parameter values of Set 1 in Table IV. These methods are explained by the captions of these two figures.

Using the parameters estimated by Method $3 \mathrm{~A}$ in Table $\mathrm{V}$ the ratios $k_{\mathrm{a}} / \lambda_{1}$ were $23.3,24.2$, and 47.2 for Sets 1,2 , and 3 , respectively. The ratio $k_{\mathrm{a}} / \lambda_{2}$ was $7.62,7.17$, and 5.67 for Sets 1,2 , and 3, respectively. For these simulations $t_{0}=0$ and Eq. (34) may be written as Eq. (42), where $B_{3}=$ $B_{1}+B_{2}$.

$$
C=B_{1} e^{-\lambda_{1} t}+B_{2} e^{-\lambda_{2} t}-B_{3} e^{-\lambda_{3} t}
$$

The following fractional area was calculated:

$$
\text { Fractional area } 1=\frac{B_{3} / k_{\mathrm{a}}}{\frac{B_{1}}{\lambda_{1}}+\frac{B_{2}}{\lambda_{2}}-\frac{B_{3}}{k_{\mathrm{a}}}}
$$

Using the estimated parameters by Methods $3 \mathrm{~A}$ in Table IV the fractional areas were $0.106,0.104$, and 0.099 for Sets 1,2 , and 3, respectively. 


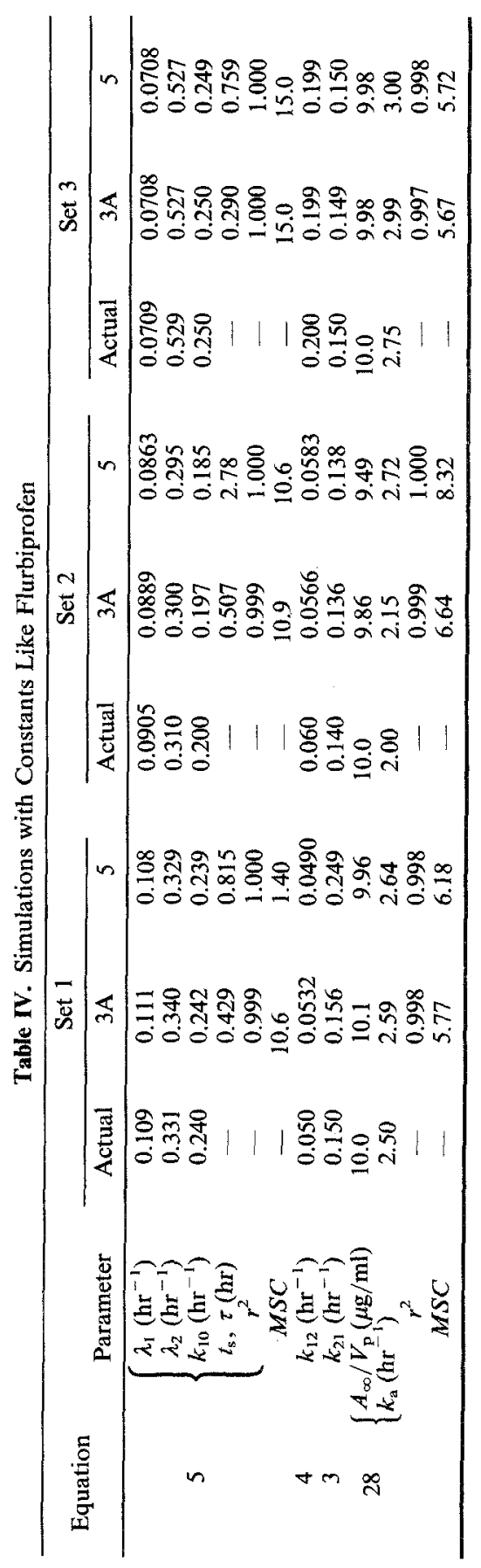




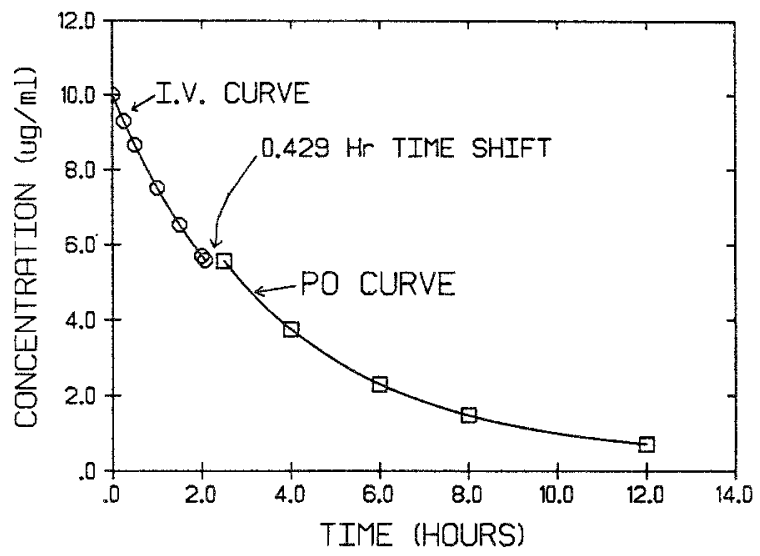

Fig. 1. Simulation which explains Method 3A. The model of Scheme 1 and the rate constants of Set 1 in Table IV were used. The iv curve and points $(O)$ are based on Eq. (17). The po points ( $\square$ ) are based on Eq. (34) with $t_{0}=0$. The postabsorptive po data from $2.5-32 \mathrm{hr}$ (only the $2.5-12 \mathrm{hr}$ data are shown in the figure) were computer-fitted to Eq. (5) with the estimate of $t_{\mathrm{s}}=0.429 \mathrm{hr}$. Thus, the fitting indicates that a shift of the po curve $0.429 \mathrm{hr}$ to the left makes the po curve line up with the iv curve.

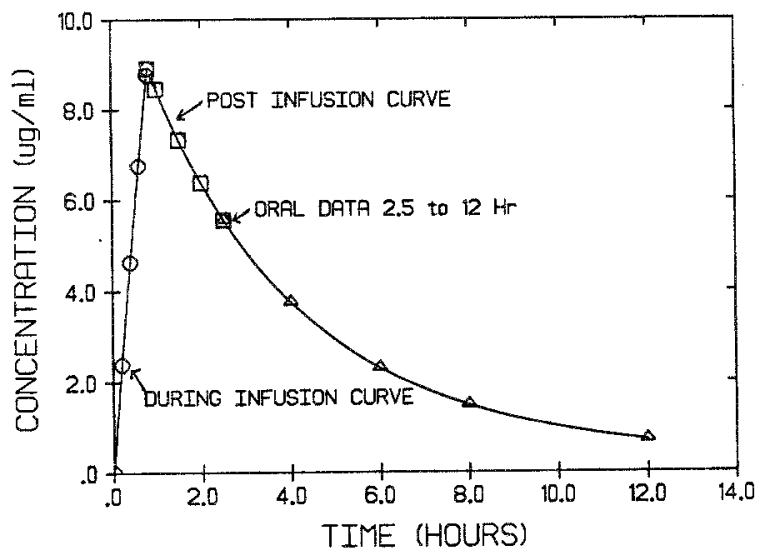

Fig. 2. Simulation which explains Method 5. The model of Scheme 1 and the rate constants of Set 1 of Table IV were used. The postabsorptive po data ( $\Delta$ points in the figure) from 2.5 $32 \mathrm{hr}$ (only the $2.5-12 \mathrm{hr}$ data are shown in the figure) were computer-fitted to Eq. (9) and $\tau=0.815 \mathrm{hr}$ was estimated. This fit was based on the oral data being treated as postinfusion data. Hence, one can infer the infusion curve $(O$ points in the figure) from $0-0.815 \mathrm{hr}$ followed by postinfusion fall off ( $\square$ ) points) from 0.815 to $2.5 \mathrm{hr}$ which was based on Eq. (19). 
Thus, the new methods work satisfactorily with the model of Scheme 3 when the ratios $k_{\mathrm{a}} / \lambda_{1}$ and $k_{\mathrm{a}} / \lambda_{2}$ and the fractional areas have magnitudes as given above. Additional simulations (not shown) indicated that as the ratios $k_{\mathrm{a}} /$ $\lambda_{1}$ and $k_{\mathrm{a}} / \lambda_{2}$ decreased and the fractional area increased, the accuracy of estimates of the disposition parameters $k_{10}, k_{21}$, and $k_{10}$ decreased.

\section{Analysis of Real Concentration-Time Data}

\section{Mesoridazine (Biexponential Disposition)}

Table $\mathrm{V}$ lists the estimated parameters of the model of Scheme 3 obtained by Methods 2, 3, 3B, and 4 for the 20 sets of human mesoridazine data analyzed. The overall mean disposition parameters were $k_{10}=$ $0.275 \mathrm{hr}^{-1}, k_{12}=0.182 \mathrm{hr}^{-1}$ and $k_{21}=0.168 \mathrm{hr}^{-1}$. The overall mean absorption parameters were $k_{\mathrm{a}}=1.21 \mathrm{hr}^{-1}$ and $t_{0}=0.206 \mathrm{hr}$. There were 280 parameter values estimated from the mesoridazine data. For each disposition parameter both the mean and range obtained by Methods 2, 3, 3B, and 4 are similar. None of the parameters estimated appeared to be dose-dependent.

The means of the $k_{\mathrm{a}} / \lambda_{1}$ ratios were $21.5,27.1$, and 13.0 for the $12.5,25$, and $50 \mathrm{mg}$ doses, respectively. The means of the $k_{\mathrm{a}} / \lambda_{2}$ ratios were $2.52,6.64$, and 3.13 for the $12.5,25$, and $50 \mathrm{mg}$ doses, respectively.

\section{Flurbiprofen (Biexponential Disposition)}

Table VI lists the mean, $C V$, and range of $k_{12}, k_{21}$, and $k_{10}$ of the model of Scheme 1 estimated by Methods 2, 3A, 3B, 4, and 5 for flurbiprofen in 12 subjects following oral administration of a solution of sodium flurbiprofen. There were 300 parameter values estimated from the flurbiprofen data.

Table VII lists results of ANOVA of the disposition parameters of flurbiprofen. The mean square for methods was not significant $(F=0.08$, $p>0.25$ ); almost all the variation was associated with subjects and rate constants. The absorption and disposition parameters of flurbiprofen were remarkably similar when determined by the different methods as can be seen by comparing the mean and range of values for each parameter by the five methods (Table VI).

In Method 3A one iterates for the parameters $k_{10}$ and $t_{\mathrm{s}}$ of Eq. (5) but holds $\lambda_{1}$ and $\lambda_{2}$ constant after the latter parameters have been obtained in the biexponential fit to Eq. (1). In Method 3B one iterates for all the parameters $\lambda_{1}, \lambda_{2}, k_{10}$, and $t_{\mathrm{s}}$ of Eq. (5). In Method 5 one iterates for $k_{10}$ and $\tau$ of Eq. (9) but hold $\lambda_{1}$ and $\lambda_{2}$ constant as in Method 3A. We used the coefficient of determination $\left(r^{2}\right)$ and the $M S C$ as measures of fit as well as the standard deviation of the estimated parameter, $s$, or the corresponding coefficient of variation, $s / P$, where $P$ is the estimated parameter value. One expects $s$ and $s / P$ to be larger for Method 3B than for Methods $3 A$ and 5 on the basis of 


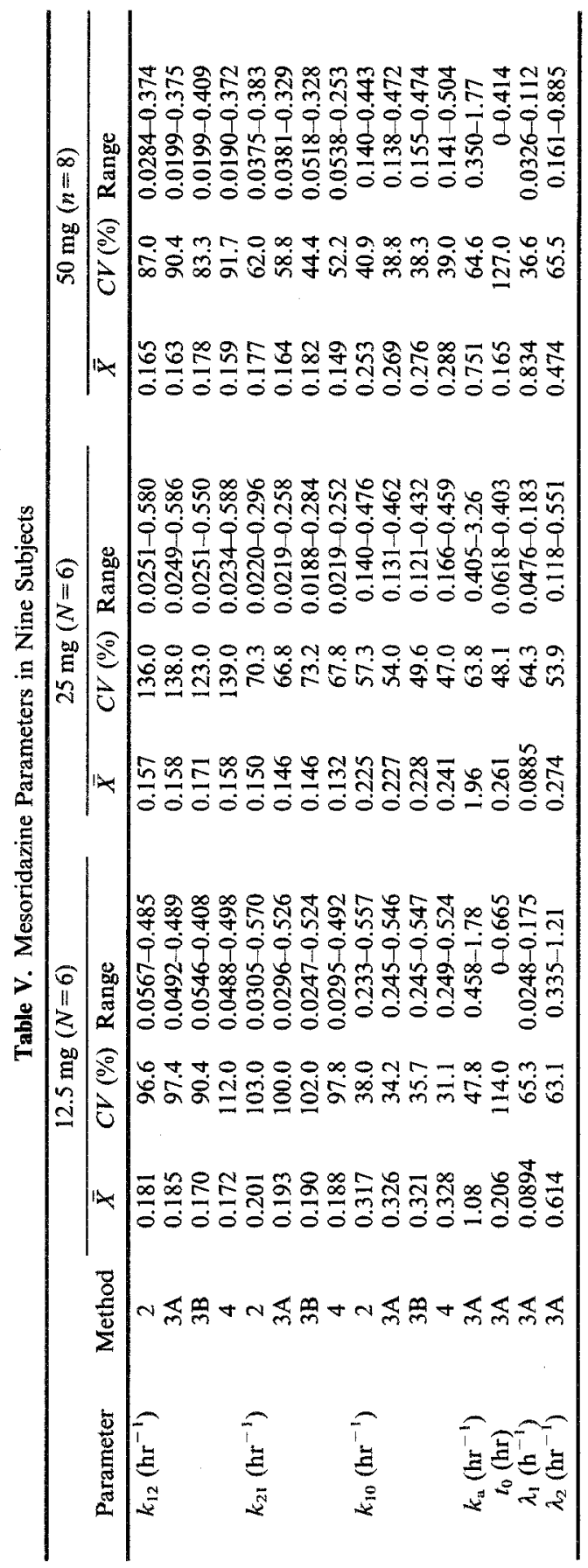


Table VI. Flurbiprofen Parameters of Twelve Subjects

\begin{tabular}{ccccc}
\hline Parameter & Method & $\bar{X}$ & $C V(\%)$ & Range \\
\hline$k_{12}\left(\mathrm{hr}^{-1}\right)$ & 2 & 0.0780 & 48.9 & $0.0422-0.156$ \\
& 3A & 0.0779 & 46.6 & $0.0419-0.145$ \\
& 3B & 0.0811 & 45.4 & $0.0420-0.153$ \\
& 4 & 0.0750 & 48.9 & $0.0379-0.149$ \\
$k_{21}\left(\mathrm{hr}^{-1}\right)$ & 5 & 0.0790 & 48.7 & $0.0398-0.158$ \\
& 2 & 0.179 & 19.8 & $0.132-0.230$ \\
& 3A & 0.179 & 21.2 & $0.137-0.235$ \\
& 3B & 0.186 & 18.4 & $0.137-0.234$ \\
$k_{10}\left(\mathrm{hr}^{-1}\right)$ & 4 & 0.169 & 18.5 & $0.131-0.218$ \\
& 5 & 0.183 & 21.0 & $0.140-0.234$ \\
& 2 & 0.237 & 17.1 & $0.150-0.308$ \\
& 3A & 0.237 & 17.6 & $0.151-0.291$ \\
$k_{\mathrm{a}}\left(\mathrm{hr}^{-1}\right)$ & 3B & 0.234 & 17.0 & $0.150-0.291$ \\
& 4 & 0.249 & 17.5 & $0.156-0.317$ \\
& 5 & 0.232 & 16.8 & $0.152-0.292$ \\
& 2 & 8.14 & 68.8 & $1.97-18.4$ \\
& 3A & 7.59 & 67.6 & $2.13-14.9$ \\
$t_{0}\left(\mathrm{hr}^{-1}\right)$ & 3B & 8.24 & 65.3 & $2.17-15.9$ \\
& 4 & 7.26 & 66.9 & $1.83-14.0$ \\
& 5 & 8.18 & 69.0 & $1.70-14.7$ \\
& 2 & 0.0394 & 83.0 & $0-0.109$ \\
& 3A & 0.0358 & 97.6 & $0-0.110$ \\
$\lambda_{1}\left(\mathrm{hr}^{-1}\right)$ & 3B & 0.0397 & 83.5 & $0-0.110$ \\
$\lambda_{2}\left(\mathrm{hr}^{-1}\right)$ & 4 & 0.0355 & 98.1 & $0-0.109$ \\
& 5 & 0.0373 & 93.2 & $0-0.110$ \\
& 3A & 0.110 & 11.4 & $0.0877-0.128$ \\
& 3A & 0.384 & 22.7 & $0.306-0.543$ \\
\hline
\end{tabular}

Table VII. ANOVA of $k_{10}, k_{12}$, and $k_{21}$ Values of Flurbiprofen

\begin{tabular}{lrllc}
\hline Source of variation & \multicolumn{1}{c}{ df } & \multicolumn{1}{c}{ SS } & \multicolumn{1}{c}{ MS } & \multicolumn{1}{c}{$F$} \\
\hline Subjects & 11 & 0.16137 & 0.01467 & 29.4 \\
Rate constants & 2 & 0.78461 & 0.39231 & 787. \\
Methods & 4 & 0.0001624 & 0.0000406 & $0.08(p>0.25)$ \\
Residual & 162 & 0.080713 & 0.0004982 & - \\
\hline Total & 179 & 1.0268554 & & \\
\hline
\end{tabular}

the number of parameters estimated and hence the degrees of freedom. For the flurbiprofen fits and the estimation of $k_{10}$, Methods 3A, 3B, and 5 gave mean $s / P$ ratios of $0.0244,0.0590$, and 0.0247 , respectively. For the fits to Eq. (31) to estimate $k_{\mathrm{a}}$ the mean $s / P$ values were $0.183,0.237$, and 0.245 , respectively, when disposition parameters of Methods $3 \mathrm{~A}, 3 \mathrm{~B}$, and 5 were used.

Figure 3 shows the fit of $C, t$ data of Subject 3 given flurbiprofen to Eq. (5) by Method 3A. Figure 4 shows the fit of the absorption data of the same subject after Method 3A parameters had been used to generate the absorption data via the Exact Loo-Riegelman method (6,7). Figure 5 shows 


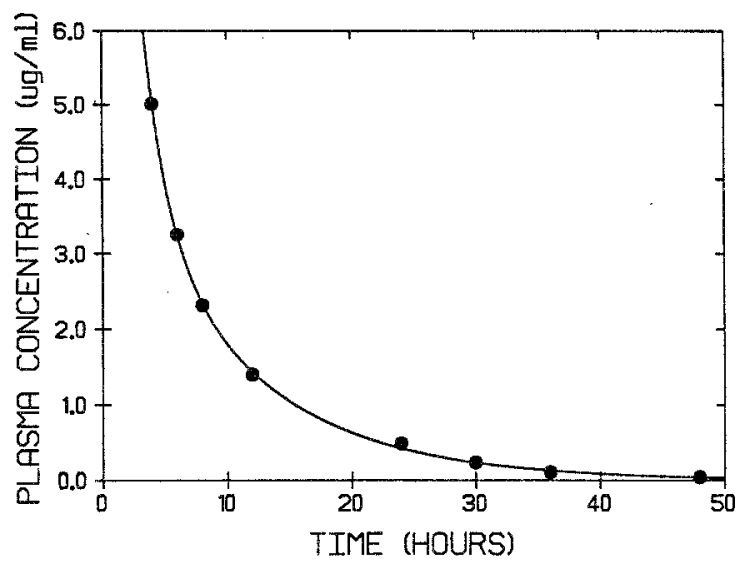

Fig. 3. Fit of the data of Subject 3 given fiurbiprofen to Eq. (5) with Method 3A. The parameters $k_{10}=0.235 \mathrm{hr}^{-1}(s=$ $0.00754)$ and $t_{\mathrm{s}}=0.535 \mathrm{hr}(s=0.0736)$ were estimated.

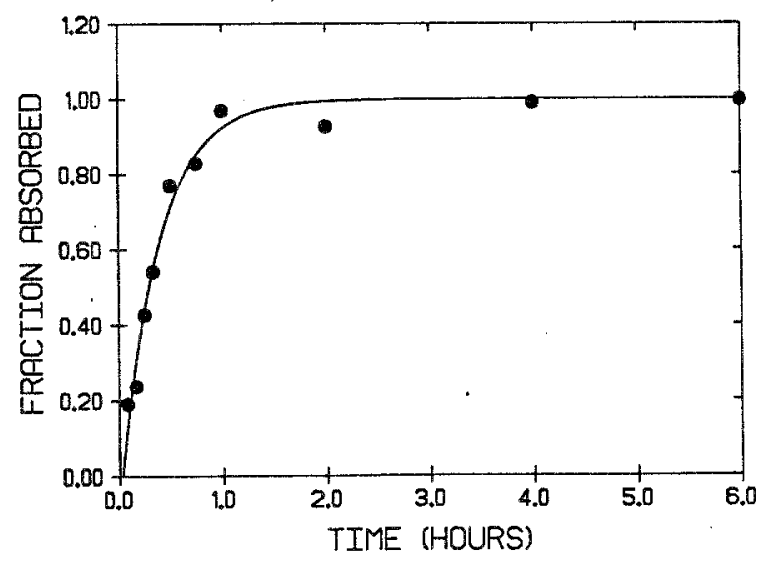

Fig. 4. Absorption plot for Subject 3 given flurbiprofen to Eq. (31) using disposition parameters obtained with Method $3 \mathrm{~A}$. The parameters $k_{\mathrm{a}}=1.84 \mathrm{hr}^{-1} \quad(s=0.250)$ and $t_{0}=$ $2.7 \times 10^{-6}(s=0.0388)$ were estimated.

reconstruction of the original data of the same subject based on Eq. (34). After such reconstructions were made the $C, t$ data were fitted by nonlinear least squares and the program MINSQ (30) to Eq. (34). Such fits gave only slight improvement in the closeness of the trend line to the points compared with the reconstructions. This is reflected by comparing $r^{2}$ and $M S C$ values for the reconstructions and fittings. The reconstructions gave mean (and range) $r^{2}$ values of $0.958(0.948-0.996)$, while the fittings gave $0.983(0.928-$ 


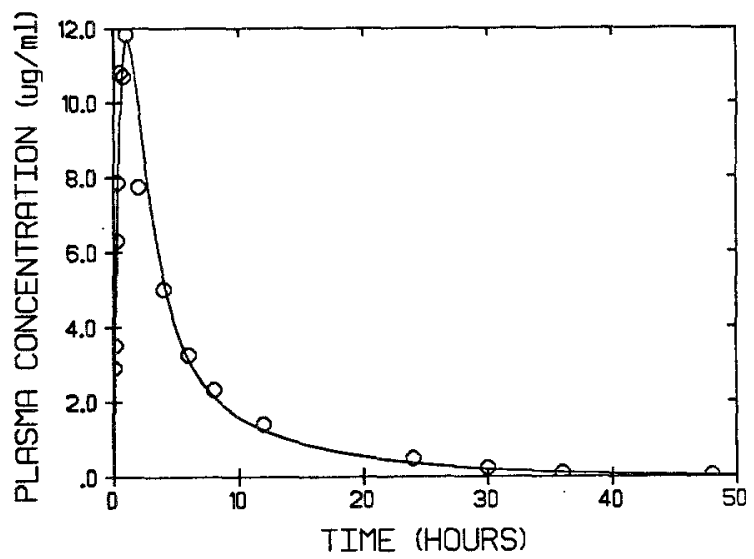

Fig. 5. Reconstruction of the original data of Subject 3 given flurbiprofen orally. The solid line is based on the model of Scheme 3, Eq. (34) and the parameter values $k_{12}=0.145 \mathrm{hr}^{-1}$, $k_{21}=0.178 \mathrm{hr}^{-1}, k_{10}=0.285 \mathrm{hr}^{-1}, k_{\mathrm{a}}=1.84 \mathrm{hr}^{-1}$, and $t_{0}=$ $2.7 \times 10^{-6}$.

$0.998)$; the corresponding $M S C$ values were 6.54 (4.26-8.05) for the reconstructions and $7.85(5.41-10.32)$ for the fittings.

The mean $k_{\mathrm{a}} /$ mean $\lambda_{1}=69$ and the mean $k_{\mathrm{a}} /$ mean $\lambda_{2}=20$ by Methods $3 \mathrm{~A}$ using values in Table VI. The individual subject fractional areas [Eq. (43)] were of the same order of magnitude as reported above for the simulations.

\section{Flunarizine (Triexponential Disposition)}

Table VIII lists the disposition parameters of the model of Scheme 2 estimated by Methods 3A and 5 for the five epileptic patients given $30 \mathrm{mg}$ single oral doses of flunarizine. Absorption parameters of Eq. (28) are also listed in Table VIII.

Table IX gives results of ANOVA of the disposition rate constants of flunarizine. The mean square for methods was not significant $(F=0.00017$, $p>0.25$ ). The absorption and disposition parameters of flunarizine were very similar when determined by the two methods as can be seen by comparing the values in Table VIII.

With the flunarizine data Method 3A was superior to Method 5 in the estimation of $k_{10}$ since the $s / P$ ratio for the former averaged 0.107 (range $0.0702-0.178$ ) compared with 0.552 (range $0.139-1.08$ ) for the latter.

The $\lambda_{1}$ values are also listed at the bottom of Table VIII. For the four patients who exhibited first-order absorption the average values of $k_{\mathrm{a}} / \lambda_{1}$, $k_{\mathrm{a}} / \lambda_{2}$, and $k_{\mathrm{a}} / \lambda_{3}$ were $970,18.4$, and 2.49 , respectively. Fractional area 
Table VIII. Flunarizine Parameters in Five Epileptic Patients

\begin{tabular}{|c|c|c|c|c|c|c|}
\hline \multirow[b]{2}{*}{ Parameter } & \multirow[b]{2}{*}{ Method } & \multicolumn{5}{|c|}{ Subject } \\
\hline & & M01LH & $\mathrm{M} 07 \mathrm{CL}$ & M03PS & M05AL & M02SL \\
\hline \multirow[t]{2}{*}{$k_{10}\left(h^{-1}\right)$} & $3 \mathrm{~A}$ & 0.0615 & 0.0467 & 0.0612 & 0.230 & 0.0383 \\
\hline & 5 & 0.0640 & 0.0485 & 0.0501 & 0.193 & 0.0331 \\
\hline \multirow{2}{*}{$k_{12}\left(\mathrm{hr}^{-1}\right)$} & $3 \mathrm{~A}$ & 0.0736 & 0.0863 & 0.0745 & 0.119 & 0.0494 \\
\hline & 5 & 0.0475 & 0.0824 & 0.0772 & 0.146 & 0.0556 \\
\hline \multirow[t]{2}{*}{$k_{13}\left(\mathrm{hr}^{-1}\right)$} & $3 \mathrm{~A}$ & 0.154 & 0.091 & 0.107 & 0.124 & 0.0494 \\
\hline & 5 & 0.188 & 0.0959 & 0.114 & 0.123 & 0.0657 \\
\hline \multirow[t]{2}{*}{$k_{21}\left(\mathrm{hr}^{-1}\right)$} & $3 \mathrm{~A}$ & 0.0581 & 0.0615 & 0.564 & 0.0901 & 0.0343 \\
\hline & 5 & 0.0507 & 0.0586 & 0.0575 & 0.100 & 0.0372 \\
\hline \multirow[t]{2}{*}{$k_{31}\left(\mathrm{hr}^{-1}\right)$} & $3 \mathrm{~A}$ & 0.00404 & 0.00166 & 0.00162 & 0.00404 & 0.0224 \\
\hline & 5 & 0.00445 & 0.00168 & 0.00194 & 0.00431 & 0.00259 \\
\hline \multirow[t]{2}{*}{$k_{\mathrm{a}}\left(\mathrm{hr}^{-1}\right)$} & $3 \mathrm{~A}$ & 0.527 & 0.877 & 0.893 & 0.708 & 61.6 \\
\hline & 5 & 0.688 & 0.780 & 0.970 & 0.402 & 57.9 \\
\hline \multirow[t]{2}{*}{$t_{0}(\mathrm{hr})$} & $3 \mathrm{~A}$ & 0.012 & 0.366 & 0.556 & 1.18 & 0.929 \\
\hline & 5 & 0.443 & 0.352 & 0.557 & 0.797 & 0.803 \\
\hline \multirow[t]{2}{*}{$A_{\infty} / V_{\mathrm{p}}(\mathrm{ng} / \mathrm{ml})$} & $3 a$ & 164 & 123 & 173 & 226 & 199 \\
\hline & 5 & 182 & 129 & 164 & 262 & 190 \\
\hline$\lambda_{1}\left(\mathrm{hr}^{-1}\right)$ & $3 a$ & 0.00110 & 0.000553 & 0.000579 & 0.0260 & 0.00829 \\
\hline$\lambda_{2}\left(\mathrm{hr}^{-1} 3\right.$ & $3 a$ & 0.0421 & 0.0342 & 0.0365 & 0.0464 & 0.0225 \\
\hline$\lambda_{3}\left(\mathrm{hr}^{-1}\right)$ & $3 a$ & 0.311 & 0.252 & 0.264 & 0.499 & 0.171 \\
\hline
\end{tabular}

Table IX. ANOVA of Flunarizine Disposition Rate Constants

\begin{tabular}{lrllcc}
\hline \multicolumn{1}{c}{ Source } & df & \multicolumn{1}{c}{ SS } & \multicolumn{1}{c}{ MS } & \multicolumn{1}{c}{$F$} & \multicolumn{1}{c}{$p$} \\
\hline Subjects & 4 & 0.03089 & 0.00723 & 7.32 & $<0.001$ \\
Rate constants & 4 & 0.06230 & 0.01558 & 15.8 & $<0.001$ \\
Methods & 1 & 0.00000169 & 0.000000169 & 0.00017 & $<0.25$ \\
Total & 49 & 0.13270 & & & \\
\hline
\end{tabular}

values obtained from Eq. (35) were of the same order of magnitude as those of the simulation reported above.

\section{Labetalol (Zero-Order Input and Biexponential Disposition)}

Table $\mathrm{X}$ lists the disposition parameters of the two-compartment open model (Scheme 1) of the individual subjects given labetalol by constant rate intestinal infusion over $4 \mathrm{hr}$. Overall mean rate constants were $k_{10}=$ $0.319 \mathrm{hr}^{-1}, k_{12}=0.558 \mathrm{hr}^{-1}$, and $k_{21}=0.298 \mathrm{hr}^{-1}$. Two-factor ANOVAs indicated that the mean square for methods was not significant $(p>0.10)$ for each rate constant when data in Table X were analyzed.

The Exact Loo-Riegelman method $(6,7)$ was applied to the $C, t$ data in the $0-4 \mathrm{hr}$ range and $A_{\infty} / V_{\mathrm{p}}$ was found to be equal to $k_{10}$ (AUC) in each case, hence Eq. (27) was used to estimate $F A$ values. For each of the nine subjects the least squares $F A$ vs. $t$ line forced through the origin was obtained; the slopes are the input rates $\left(k_{0} / A_{\infty}\right.$ in fraction $\left./ \mathrm{hr}\right)$ listed in the last two columns of Table $X$. The theoretical rate $=1 / 4=0.250$ hence the 
Table X. Labetalol Disposition and Input Rate Constants (Methods 2 and 4)

\begin{tabular}{|c|c|c|c|c|c|c|c|c|c|c|}
\hline \multirow[b]{2}{*}{ Subject } & \multirow{2}{*}{$\frac{A U M C}{A U C}$} & \multirow[b]{2}{*}{$V_{\mathrm{p}}(\mathbf{L})$} & \multicolumn{2}{|c|}{$k_{10}\left(\mathrm{hr}^{-1}\right)$} & \multicolumn{2}{|c|}{$k_{12}\left(\mathrm{hr}^{-1}\right)$} & \multicolumn{2}{|c|}{$k_{21}\left(\mathrm{hr}^{-1}\right)$} & \multicolumn{2}{|c|}{$\begin{array}{c}\text { Input rate } \\
{\text { (fraction } / \mathrm{hr})^{a}}\end{array}$} \\
\hline & & & 2 & 4 & 2 & 4 & 2 & 4 & 2 & 4 \\
\hline 1 & 15.17 & 1465.0 & 0.180 & 0.229 & 0.260 & 0.333 & 0.105 & 0.163 & 0.257 & 0.261 \\
\hline 2 & 10.15 & 2910.0 & 0.211 & 0.208 & 0.164 & 0.164 & 0.216 & 0.219 & 0.288 & 0.274 \\
\hline 3 & 12.65 & 2171.0 & 0.200 & 0.232 & 0.254 & 0.347 & 0.165 & 0.232 & 0.264 & 0.268 \\
\hline 4 & 9.74 & 1420.0 & 0.252 & 0.249 & 0.241 & 0.259 & 0.240 & 0.269 & 0.258 & 0.264 \\
\hline 5 & 8.49 & 1645.0 & 0.399 & 0.462 & 0.628 & 0.785 & 0.355 & 0.416 & 0.254 & 0.239 \\
\hline 6 & 11.34 & 865.3 & 0.492 & 0.518 & 1.447 & 1.453 & 0.378 & 0.387 & 0.252 & 0.243 \\
\hline 7 & 9.71 & 2287.0 & 0.292 & 0.260 & 0.270 & 0.217 & 0.241 & 0.207 & 0.248 & 0.254 \\
\hline 8 & 10.42 & 1366.0 & 0.308 & 0.329 & 0.481 & 0.523 & 0.306 & 0.302 & 0.245 & 0.238 \\
\hline 9 & 8.35 & 617.0 & 0.429 & 0.494 & 1.024 & 1.180 & 0.564 & 0.587 & 0.263 & 0.252 \\
\hline $\bar{X}$ & 10.67 & 1638.0 & 0.307 & 0.331 & 0.530 & 0.585 & 0.286 & 0.309 & 0.259 & 0.255 \\
\hline$C V(\%)$ & 20.1 & 43.8 & 36.0 & 37.9 & 82.5 & 78.6 & 47.5 & 43.1 & 4.88 & 5.09 \\
\hline
\end{tabular}

${ }^{a}$ Theoretical value $=0.250$.

mean rates of 0.259 and 0.255 for Methods 2 and 4, respectively, have biases of 3.6 and $2.0 \%$, respectively; there were low coefficients of variation of 4.88 and $5.09 \%$, respectively, also. Figure 6 shows an example of one of the input plots. The small scatter of the points about the line for both methods and all nine subjects may be gauged from the fact that for Method 4 the $s / P$ ratio averaged 0.0306 with a range of $0.0123-0.0605$ and similar results were obtained with Method 2.

Figure 7 is a reconstruction of the labetalol $C, t$ data of Subject 6 using disposition parameters obtained via Method 2.

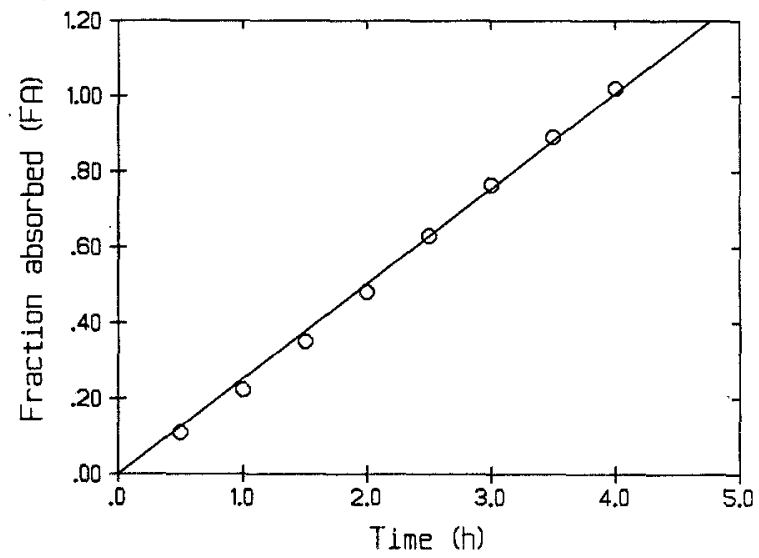

Fig. 6. Input plot for Subject 6 given labetalol based on disposition parameters obtained with Method 2. The slope of the line is the input $k_{0} / A_{\infty}$ value and is equal to 0.252 with $s=$ 0.0123 ; the theoretical input rate is 0.250 . 


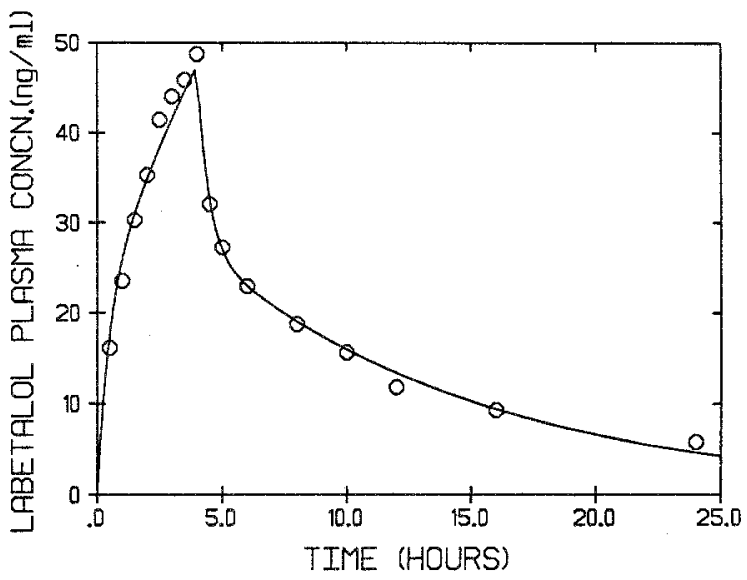

Fig. 7. Reconstruction of the labetalol data of Subject 6 where the disposition parameters had been obtained via Method 2 (Table X) and Eqs. (38) and (39) were used.

\section{Diazepam (Triexponential Disposition and Biexponential Absorption)}

Table XI lists the disposition and absorption parameters estimated from oral $C, t$ data of four subjects who were administered $10 \mathrm{mg}$ doses of diazepam. $A_{\mathrm{T}} / V_{\mathrm{p}}$ values obtained via the Exact Loo-Riegelman method $(6,7)$ were computer-fitted to Eq. (29) and the estimates of $k_{1}, k_{2}$, and $A_{\infty} /$ $V_{\mathrm{p}}$ obtained are summarized in Table XI.

Table XII gives results of ANOVA of the diazepam disposition parameters for Subjects 1-3 only since Subject 4 gave bi- rather than triexponential disposition after iv administration. Thus disposition was nonconstant for Subject 4 . The mean square for methods was not significant $(F=0.33$, $p>0.25$ ) indicating that disposition was constant intrasubject for Subjects 1-3. Table XIII gives results of ANOVA of the diazepam absorption parameters of the four subjects. Again the mean square for methods was not significant $(F=0.45, p>0.25)$.

The overall mean rate constants for diazepam were $k_{10}=0.123 \mathrm{hr}^{-1}$, $k_{12}=1.77 \mathrm{hr}^{-1}, k_{13}=0.384 \mathrm{hr}^{-1}, k_{21}=0.959 \mathrm{hr}^{-1}, k_{31}=0.0629 \mathrm{hr}^{-1}, k_{1}=$ $1.66 \mathrm{hr}^{-1}$, and $k_{2}=5.05 \mathrm{hr}^{-1}$.

In the estimation of $k_{10}$ of diazepam Methods $3 \mathrm{~A}$ and 5 gave mean $s /$ $P$ ratios of 1.29 and 1.52 , respectively. In the estimation of $Z$, Methods $3 \mathrm{~A}$ and 5 gave mean $s / P$ ratios of 0.934 and 1.25 , respectively. Hence, Method $3 \mathrm{~A}$ was superior to Method 5 from this point of view, but the difference between the methods was not nearly as great as in the case of flunarizine.

In the case of the model of Scheme 6 and the five-term polyexponential Eq. (40), it is much more difficult to estimate a "fractional area" as was 


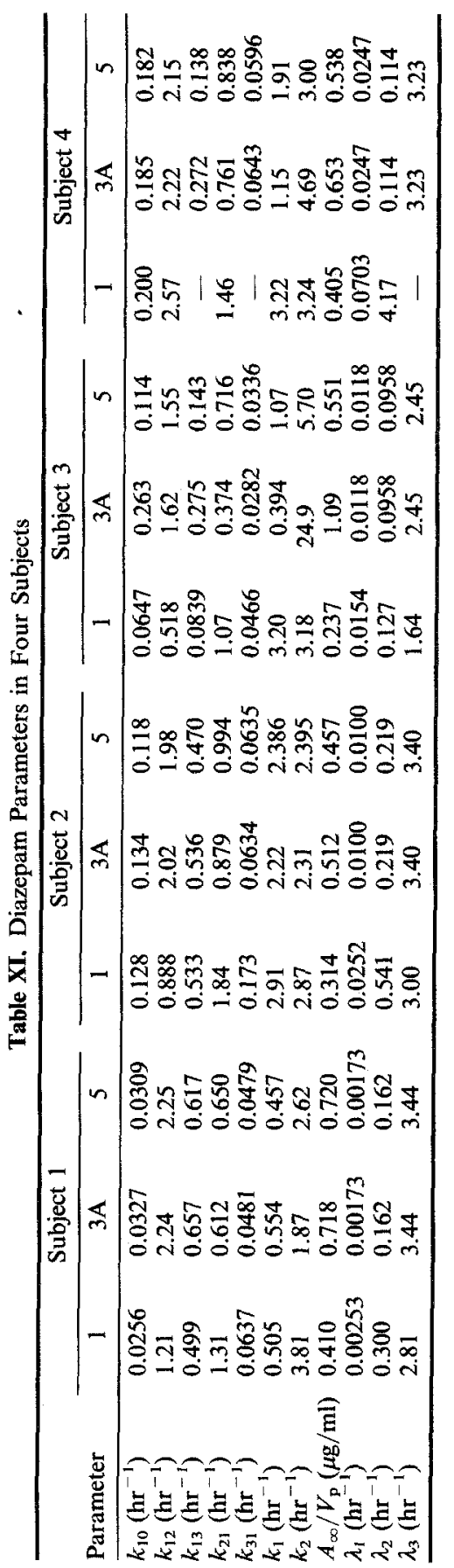


Table XII. ANOVA of Disposition Parameters of Diazepam for Subjects 1-3 $3^{a}$

\begin{tabular}{lrrccc}
\hline \multicolumn{1}{c}{ Source } & df & SS & MS & $F$ & $p$ \\
\hline Subjects & 2 & 0.6036 & 0.3018 & 2.57 & \\
Rate constants & 4 & 14.8740 & 3.7185 & 31.6 & \\
Methods & 2 & 0.0782 & 0.0391 & 0.33 & $>0.25$ \\
Residual & 36 & 4.2352 & 0.1176 & & \\
Total & 44 & 19.7910 & & & \\
\hline
\end{tabular}

${ }^{a}$ Subject 4 could not be included since Method I gave biexponential rather than triexponential disposition.

Table XIII. ANOVA of Diazepam Absorption Parameters in Four Subjects

\begin{tabular}{lrrrrr}
\hline \multicolumn{1}{c}{ Source } & df & \multicolumn{1}{c}{ SS } & MS & \multicolumn{1}{c}{$F$} & $p$ \\
\hline Subjects & 3 & 101.8286 & 33.9429 & 3.41 & \\
Parameter & 2 & 223.1167 & 111.5584 & 11.2 & \\
Methods & 4 & 18.0155 & 4.5039 & 0.45 & $>0.25$ \\
Residual & 50 & 497.2930 & & & \\
Total & 59 & 840.2538 & & & \\
\hline
\end{tabular}

done using Eqs. (42) and (43) based on the model of Scheme 3. Intravenous diazepam data was fitted by nonlinear least squares using the program RSTRIP (30) to the triexponential Eq. (44).

$$
C=C_{1} e^{-\lambda_{1} t}+C_{2} e^{-\lambda_{2} t}+C_{3} e^{-\lambda_{3} t}
$$

From $C_{i} \mathrm{~s}$ and $\lambda_{i} \mathrm{~s}$ of the four subjects a different Fractional area 2 was estimated as follows

$$
\text { Fractional area } 2=\frac{C_{1} / \lambda_{1}}{\frac{C_{1}}{\lambda_{1}}+\frac{C_{2}}{\lambda_{2}}+\frac{C_{3}}{\lambda_{3}}}
$$

The five-term polyexponential Eq. (40) for oral administration may be written as Eq. (46).

$$
C=B_{1} e^{-\lambda_{1} t}+B_{2} e^{-\lambda_{2} t}+B_{3} e^{-\lambda_{3} t}+B_{4} e^{-k_{1} t}+B_{5} e^{-k_{2} t}
$$

From the $B_{i} \mathrm{~s}$ and $\lambda_{i} \mathrm{~s}$ of the four subjects given diazepam orally (parameters which were needed are shown in Table XI) a Fractional area 3 was estimated 
as follows

$$
\text { Fractional area } 3=\frac{B_{1} / \lambda_{1}}{\frac{B_{1}}{\lambda_{1}}+\frac{B_{2}}{\lambda_{2}}+\frac{B_{3}}{\lambda_{3}}+\frac{B_{4}}{k_{1}}+\frac{\beta_{5}}{k_{2}}}
$$

The intravenous data gave a mean Fractional area 2 of 0.894 with a coefficient of variation of $11.2 \%$. The oral data gave a mean Fractional area 3 of 0.891 with a coefficient of variation of $21.9 \%$. This indicates that the intravenous and oral data were very comparable. Now $1-0.895=0.105$, a value very similar to the Fractional area 1 reported above under Simulations and also under Flurbiprofen.

Figure 8 shows reconstructions of the oral diazepam data of Subject 3 using parameters estimated by the three methods. The peak concentration was underestimated in each case. The same type of underestimation occurred with data of the other three subjects. However, when all four data sets were fitted by nonlinear least squares to a five-term polyexponential equation using the program RSTRIP (30) the same type of underestimation of the peak concentration occurred in each case.

Evidence that the new methods are superior to polyexponential fitting as done classically was provided by the diazepam results. Figure 9 , upper panel, shows a log-log plot of the exponent $\left(\lambda_{1}\right)$ obtained by triexponential fitting of postabsorptive oral diazepam data to $\mathrm{Eq}$. (10) vs. the exponent $\left(\lambda_{1}\right)$ obtained by triexponential fitting of bolus iv diazepam data to Eq. (44) for all four subjects. The least squares line is: $\ln Y=1.096 \ln X-0.217$ with $r^{2}=0.976$; the corresponding line without logarithms is: $Y=$ $0.991 \mathrm{X}+0.0413$ with $r^{2}=0.911$. There are only 11 rather than 12 points in each of these figures since the intravenous data of Subject 4 was fitted by a biexponential rather than a triexponential equation. Figure 9, lower panel, shows a $\log -\log$ plot of the exponent $\left(\lambda_{1}\right.$ or $\left.k_{i}\right)$ obtained from the RSTRIP (30) five-term polyexponential fit of all the $C, t$ oral data vs. the exponent $\left(\lambda_{1}\right)$ obtained by triexponential fitting of bolus iv diazepam data for all four subjects. The least squares line is : $\ln Y=0.7295 \ln X-0.992$ with $r^{2}=0.738$; the corresponding line without logarithms is: $\mathrm{Y}=0.292 \mathrm{X}+0.136$ with $r^{2}=$ 0.673 . The upper panel of Fig. 9 supports the lack of significance of the methods mean square of Table XII. With the five-term RSTRIP fit of the oral data it was difficult to assign each of the five exponents to disposition or absorption and the lower panel of Fig. 9 is about the best results which could be obtained. Thus with triexponential fitting of postabsorptive $C, t$ data the exponents obtained correlate much better with the exponents obtained in fitting iv data of the same subjects than do the exponents obtained in classical fitting of all $C, t$ data to a polyexponential equation. 

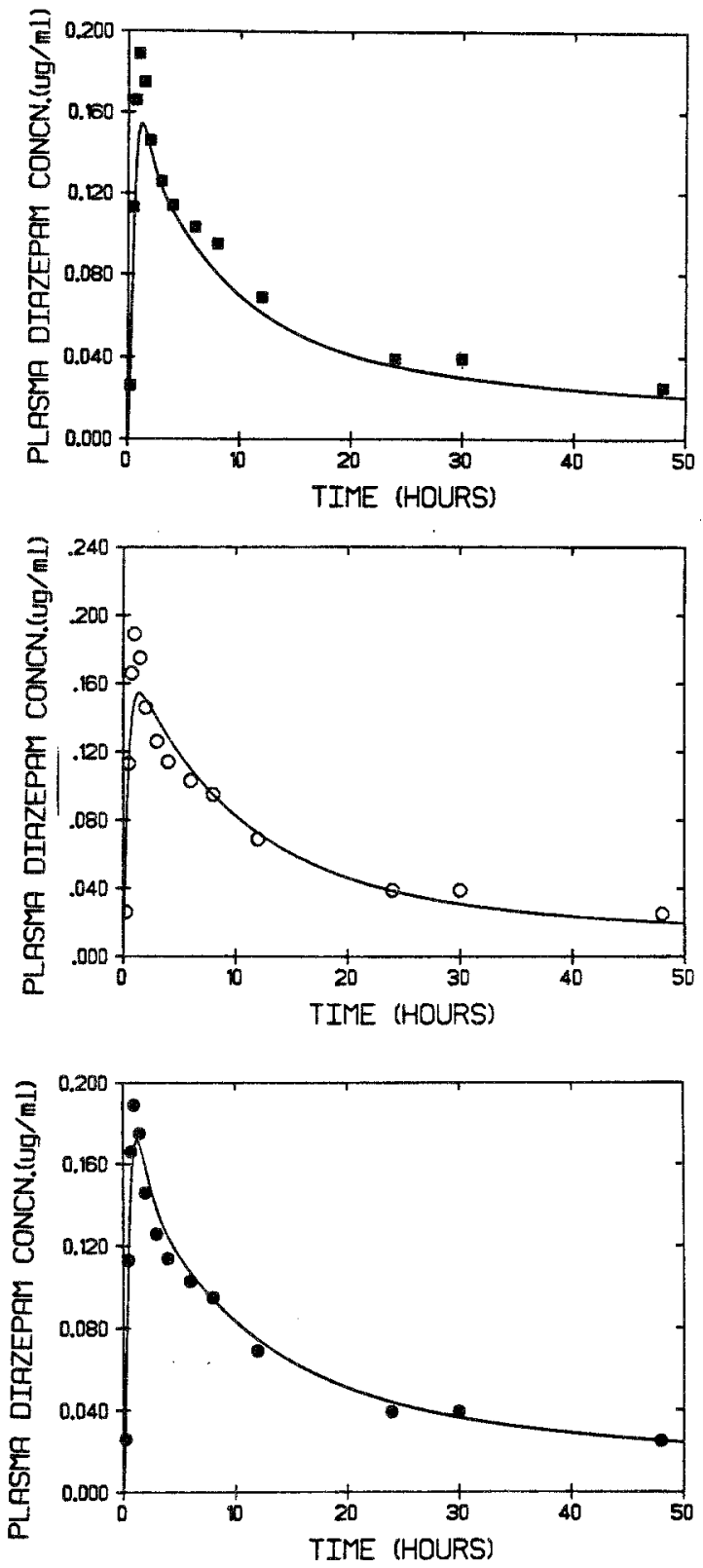

Fig. 8. Reconstructions of the diazepam $C, t$ data of Subject 3 using parameter values estimated by Methods 1 (top), 3A (middle), and 5 (bottom). The peaks were underestimated by all methods (see text). 

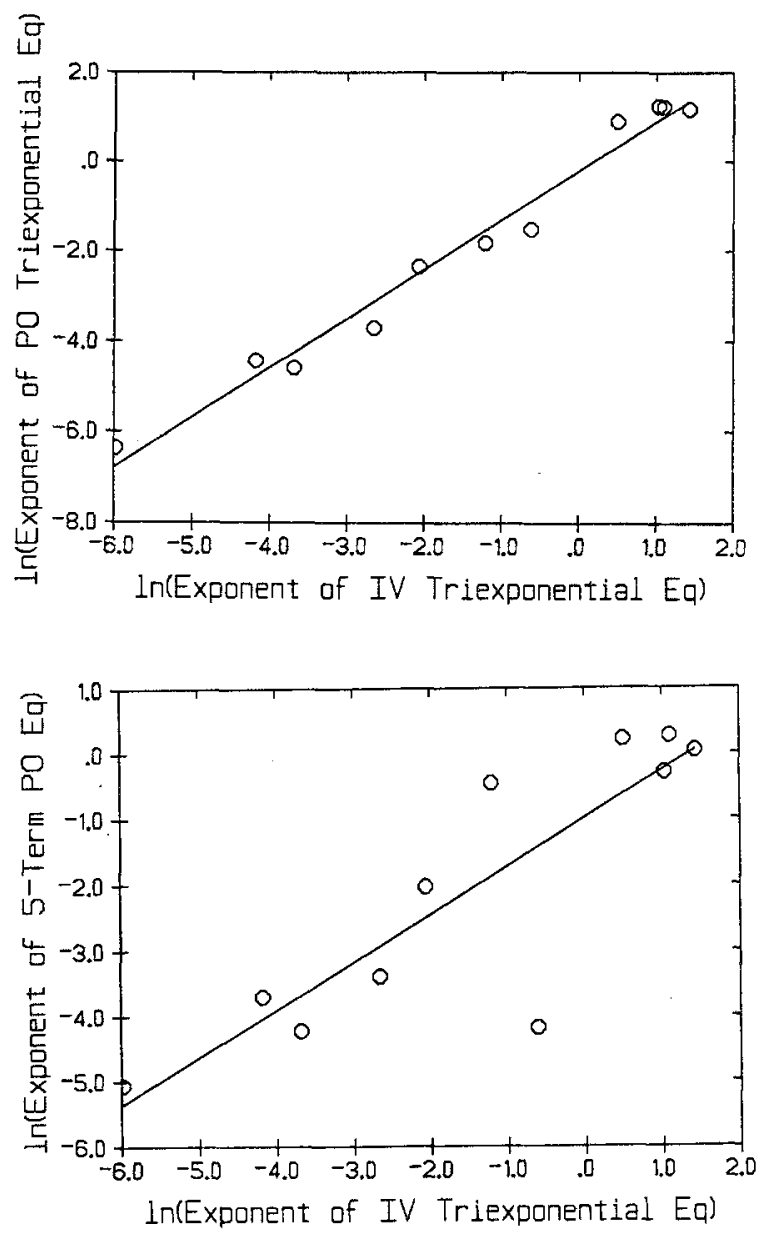

Fig. 9. Evidence from the diazepam results that the new method of fitting postabsorptive oral data is better than the classical method of polyexponential fitting of all $C, t$ data. See text at end of Results section for details.

\section{DISCUSSION}

\section{Advantages and Disadvantages}

The advantages of the new methods are:

1. Multicompartmental model disposition parameters are obtained from extravascular data without intravenous data obviating any assumption of constancy of disposition as in classical methods. 
2. Absorption analysis can follow one or more disposition methods leading to elaboration of a complete compartment model from a single set of extravascular concentration-time data.

3. Existing microcomputer software available in U.S. market is satisfactory to apply the methods.

4. Once the absorption and disposition parameters have been estimated a reconstruction trend line may be drawn through the original $C, t$ data.

5. Once the complete compartment model has been elaborated from a set of extravscular $C, t$ data then one can infer intravenous $C, t$ data and derive parameters of system analysis $(33,39-43)$ from extravascular data.

6. Absorption plots may be made from multicompartmental extravascular data only, providing quantitation in determining the effects of formulation factors on performance of rapid release dosage forms in animals and human beings.

7. The true normalized input rate may be estimated as evidenced by our results with labetalol.

8. If constancy of disposition is assumed one may use the new methods with $C, t$ data from a rapid-release dosage form such as a solution to determine disposition parameters then use these with $C, t$ data from a sustainedrelease dosage form to obtain absorption kinetics of the sustained-release dosage form. Thus, intravenous administration is avoided.

The disadvantages of the new methods are:

1. They are only applicable to linear data.

2. They are only applicable to $C, t$ data obtained from rapid-release dosage forms. Ratios $k_{\mathrm{a}} / \lambda_{1}$ and $k_{\mathrm{a}} / \lambda_{2}$ and fractional areas have been reported and aid in quantitating how rapid absorption must be.

3. They do not determine absolute bioavailability.

4. The methods provide the wrong compartment model if there are vanishing exponential terms (44).

\section{Preferred Methods}

When one has no prior knowledge of input kinetics, then Method 3A is the preferred method. Method 3A produced smaller standard deviations of estimated parameters than Method 5. When input is known to be zero order and the input time, $\tau$, is known then Methods 2 and 4 are preferred as in the case of labetalol administered by intestinal infusion.

Method 3B gave much larger standard deviations of the estimated parameters than Method 3A because the number of parameters estimated with Method 3B is larger, and hence the degrees of freedom smaller, than with Method 3A. However, the parameter values estimated via Methods 3A and $3 \mathrm{~B}$ from the same set of data were not significantly different. 


\section{Absorption Kinetics}

Fifty sets of real extravascular $C, t$ data were analyzed, each set by from two to six different methods, making a total of 198 compartment model analyses. In all cases absorption was described well by one of three models, namely, either simple first-order, two consecutive first-order processes, or a zero-order process. However, the description of absorption by a kinetic equation is not essential to the process and, conceivably, one could limit analysis of a set of $C, t$ data to a plot of $A_{\mathrm{T}} / V_{\mathrm{p}}$ vs. time, which could not be described by a simple kinetic equation.

\section{Constancy of Disposition}

Data from the literature which are summarized in Tables I and II indicate that disposition is often not constant intrasubject. Our analysis of the diazepam data, where intravenous as well as oral data were available, indicate that disposition was constant intrasubject for 3 of 4 subjects. The important point is that the new methods provide a means of testing the hypothesis of constancy of disposition.

\section{GLOSSARY}

$\begin{array}{ll}\text { ANOVA } & \text { Analysis of variance. } \\ A U C & \text { Area under the } C, t \text { curve from zero to infinite time. } \\ A U M C & \text { Area under the first moment curve [see Eq. (13)]. } \\ A_{\infty} & \text { The total amount of drug which reaches the systemic } \\ & \text { circulation }=\mathrm{F} \cdot \mathrm{D} . \\ A_{\mathrm{T}} & \text { The amount of drug which reaches the systemic } \\ & \text { circulation to specific time } T . \\ B_{i} & \text { The coefficient of the } i \text { th term }(i=1,2 \text {, or } 3 \text { ) of the } \\ C & \text { polyexponential equation fitting extravascular data. } \\ & \text { The observed drug concentration (in plasma, serum, or } \\ C_{i} & \text { whole blood). } \\ C L & \text { The coefficient of the } i \text { th polyexponential term when } \\ \text { Free } C L & \text { bolus intravenous data are fitted. } \\ C L_{\mathrm{r}} & \text { Clearance }=D / A U C \text { of total drug. } \\ C_{\mathrm{T}} & \text { Clearance of free drug }=D / A U C \text { of free drug. } \\ \hat{C}_{\mathrm{T}} & \text { Renal clearance. } \\ C V & \text { The observed drug concentration at specific time } T . \\ & \text { The model-predicted drug concentration at specific time } \\ & T .\end{array}$




\begin{tabular}{|c|c|}
\hline$D$ & Dose of drug. \\
\hline$F$ & Bioavailability \\
\hline$F A$ & Fraction of the available dose (F.D.) [Eq. (27)]. \\
\hline $\begin{array}{l}k_{10}, k_{12}, k_{21} \\
\quad k_{13}, k_{31}\end{array}$ & Disposition rate constants. \\
\hline$k_{i j}$ & First-order model rate constant. \\
\hline$k_{1}, k_{2}$ & $\begin{array}{l}\text { Absorption rate constants when absorption is } \\
\text { biexponential. }\end{array}$ \\
\hline$k_{\mathrm{a}}$ & $\begin{array}{l}\text { Absorption rate constant when absorption is } \\
\text { monoexponential. }\end{array}$ \\
\hline$k_{0}$ & A zero-order input rate constant (mass/time). \\
\hline$\lambda_{i}$ & Exponent of polyexponential equation $(i=1,2$, or 3$)$ \\
\hline$A U M C / A U C$ & $\begin{array}{l}\text { The mean residence time of the body after extravascular } \\
\text { administration including the } M I T \text {. }\end{array}$ \\
\hline$M I T$ & $\begin{array}{l}\text { The mean input time from the absorption or input site(s) } \\
\text { (45). }\end{array}$ \\
\hline$M R T$ & The mean residence time $=(A U M C / A U C)-M I T$ \\
\hline$p$ & $\begin{array}{l}\text { The number of parameters estimated in a nonlinear least } \\
\text { squares fitting. }\end{array}$ \\
\hline$P$ & $\begin{array}{l}\text { The parameter value estimated in a nonlinear least } \\
\text { squares fitting. }\end{array}$ \\
\hline$r^{2}$ & $\begin{array}{l}\text { The coefficient of determination }= \\
\left.1-\sum \operatorname{dev}^{2} / s_{y}^{2} \text { where } s_{y}^{2}=\sum \mathrm{Y}^{2}-\left(\sum \mathrm{XY}\right)^{2} / n\right)\end{array}$ \\
\hline$s$ & $\begin{array}{l}\text { The standard deviation of an estmated parameter in } \\
\text { nonlinear least squares fitting. }\end{array}$ \\
\hline$M S C$ & $\ln \frac{\sum_{i=1}^{n} w_{i}\left(Y_{\mathrm{obsi}}-\overline{Y_{\mathrm{obs}}}\right)^{2}}{\sum_{i=1}^{n} w_{i}\left(Y_{\mathrm{obsi}}-Y_{\mathrm{calci}}\right)^{2}}-\frac{2 p}{n}$ \\
\hline$t$ & Time after administration. \\
\hline$t_{0}$ & The lag time before absorption apparently commences. \\
\hline$t_{\mathrm{s}}$ & $\begin{array}{l}\text { The time needed to shift the postabsorptive oral curve to } \\
\text { the left so it coincides with the bolus intravenous curve } \\
\text { (see Fig. 1). }\end{array}$ \\
\hline$T$ & Some specific time $t$ \\
\hline$\tau$ & $\begin{array}{l}\text { The duration of an infusion or zero-order input [see } \\
\text { Methods } 4 \text { and } 5 \text { and Eqs. (8), (9), and (12)]. }\end{array}$ \\
\hline$V_{\mathrm{p}}$ & The volume of the central (\#1) compartment. \\
\hline$V_{\beta}$ & Volume of distribution beta $=V_{\mathrm{d} \text { area }}=D / 1(A U C)$ \\
\hline$w_{i}$ & Weight of $i$ th data point in a nonlinear least squares fit. \\
\hline
\end{tabular}


$Y_{i} \quad$ The coefficient of the $i$ th polyexponential term when postinfusion data have been fitted.

Z $\quad k_{21}+k_{31}$.

\section{APPENDIX}

Table A. Plasma Concentration of Labetalol in Nine Subjects

\begin{tabular}{|c|c|c|c|c|c|c|c|c|c|}
\hline \multirow{2}{*}{$\begin{array}{l}\text { Time } \\
\text { (hr) }\end{array}$} & \multicolumn{9}{|c|}{ Plasma concentration of labetalol $(\mathrm{ng} / \mathrm{ml})$} \\
\hline & 1 & 2 & 3 & 4 & 5 & 6 & 7 & 8 & 9 \\
\hline 0.00 & 0.00 & 0.00 & 0.00 & 0.00 & 0.00 & 0.00 & 0.00 & 0.00 & 0.00 \\
\hline 0.50 & 17.77 & 15.28 & 12.59 & 17.01 & 10.84 & 16.14 & 6.83 & 8.05 & 24.85 \\
\hline 1.00 & 34.96 & 29.40 & 16.70 & 40.33 & 17.74 & 23.51 & 19.96 & 28.34 & 40.48 \\
\hline 1.50 & 37.71 & 25.18 & 23.19 & 43.40 & 20.67 & 30.29 & 25.58 & 25.92 & 63.28 \\
\hline 2.00 & 45.49 & 29.99 & 36.76 & 47.02 & 24.58 & 35.27 & 30.74 & 26.27 & 58.16 \\
\hline 2.50 & 51.37 & 33.72 & 37.94 & 49.01 & 22.80 & 41.43 & 32.02 & 40.12 & 68.72 \\
\hline 3.00 & 52.02 & 40.99 & 40.09 & 75.58 & 25.34 & 44.03 & 36.39 & 38.12 & 68.01 \\
\hline 3.50 & 55.51 & 31.30 & 41.55 & 59.83 & 44.16 & 45.87 & 42.30 & 70.43 & 82.52 \\
\hline 4.00 & 57.61 & 34.04 & 36.22 & 59.56 & 34.97 & 48.76 & 42.29 & 56.38 & 76.03 \\
\hline 4.50 & 44.34 & 36.72 & 27.76 & 53.58 & 25.80 & 32.06 & 37.15 & 42.25 & 56.55 \\
\hline 5.00 & 35.50 & 21.92 & 28.52 & 42.41 & 20.22 & 27.22 & 33.18 & 33.87 & 52.95 \\
\hline 6.00 & 32.00 & 28.46 & 18.18 & 35.15 & 16.58 & 22.91 & 18.44 & 26.62 & 45.11 \\
\hline 8.00 & 18.78 & 16.32 & 17.02 & 23.77 & 11.98 & 18.75 & 14.43 & 18.06 & 32.54 \\
\hline 10.00 & 16.98 & 9.45 & 12.43 & 21.58 & 9.37 & 15.64 & 12.27 & 15.65 & 23.85 \\
\hline 12.00 & 12.76 & 9.78 & 10.12 & 14.50 & 6.42 & 11.81 & 8.61 & 10.12 & 18.44 \\
\hline 16.00 & 9.41 & 7.67 & 6.76 & 9.84 & 4.62 & 9.29 & 4.71 & 10.48 & 10.58 \\
\hline 24.00 & 8.54 & 2.88 & 5.67 & 5.30 & 2.32 & 5.80 & 2.96 & 3.61 & 6.39 \\
\hline
\end{tabular}




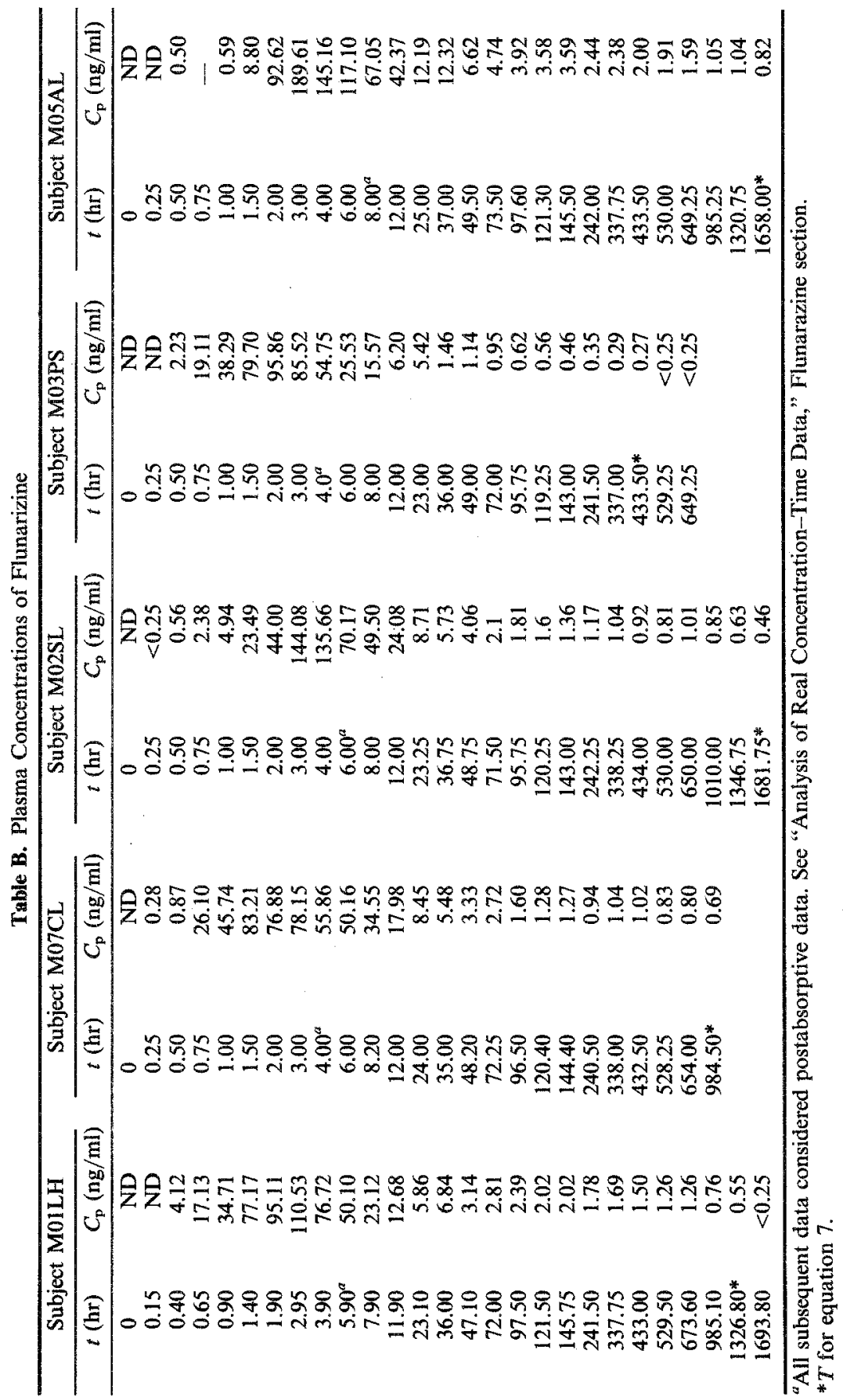




\section{REFERENCES}

1. A. Rescigno and G. Segre. Drug and Tracer Kinetics, Blaisdell, Waltham, MA, 1966.

2. J. G. Wagner. Fundamentals of Clinical Pharmacokinetics, 1st ed., Drug Intelligence Publications, Hamilton, IL, 1975, p. 461. (Ref. 2a, p. 88)

3. M. Gibaldi and D. Perrier. Pharmacokinetics, 2nd ed., Marcel Dekker, New York, 1982.

4. J. G. Wagner and E. Nelson. Percent absorbed time plots derived from blood level and/ or urinary excretion data. J. Pharm. Sci. 52:610-611 (1983).

5. J. Loo and S. Riegelman. New method for calculating the intrinsic absorption rate of drugs. J. Pharm. Sci. 57:918-928 (1968).

6. J. G. Wagner. Pharmacokinetics absorption plots from oral data alone or oral/intravenous data and an Exact Loo-Riegelman equation. J. Pharm. Sci. 72:838-845 (1983).

7. J. H. Proost. Wagner's Exact Loo-Riegelman equation: The need for a criterion to choose between the linear and logarithmic trapezoidal rule. J. Pharm. Sci. 74:793-794 (1985).

8. P. Veng-Pedersen. An algorithm and computer program for deconvolution in linear pharmacokinetics. J. Pharmacokin. Biopharm. 8:463-481 (1980).

9. W. R. Gillespie and P. Veng-Pedersen. A polyexponential deconvolution method: Evaluation of "gastrointestinal bioavailability" and mean in vitro dissolution time of some ibuprofen dosage forms. J. Pharmacokin. Biopharm. 13:289-307 (1985).

10. W. R. Gillespie and Veng-Pedersen. Gastrointestinal bioavailability: Determination of in vivo release profile of solid oral dosage forms by deconvolution. Biopharm. Drug. Dispos. 6:351-355 (1985).

11. P. Veng-Pedersen and W. R. Gillespie. A note on appropriate constraints on the initial input response when applying deconvolution. J. Pharmacokin. Biopharm. 14:441-447 (1986).

12. J. G. Wagner, J. I. Northam, and W. T. Sokolski. Biological half-lives of the antibiotic lincomycin observed in repetitive experiments in the same subjects. Nature 207:201-202 (1965).

13. J. G. Wagner. Intrasubject variation in elimination half-lives of drugs which are appreciably metabolized. J. Pharmacokin. Biopharm. 1:165-173 (1973).

14. A. P. Alvares, A. Kappas, J. L. Eisman, K. E. Anderson, C. B. Pantuck, E. J. Pantuck, K. C. Hsiao, W. A. Garland, and A. H. Conney. Intraindividual variation in drug disposition. Clin. Pharmacol. Ther. 26:247-255 (1979).

15. M. Eichelbaum and A. Smogyi. Inter- and intra-subject variation in first-pass elimination of highly cleared drugs during chronic dosing: Studies with deuterated verapamil. Eur. J. Clin. Pharmacol. 26:47-53 (1984).

16. A. Grahnen, M. Hammarlund, and T. Lundquist. Implications of intraindividual variability in bioavailability studies of furosemide. Eur. J. Clin. Pharmacol. 27:595-602 (1984).

17. A. A. Halazo, W. A. Colburn, J. H. Gustafson, R. L. Young, and M. Parsonnet. Pharmacokinetics of bumetanide following intravenous, intramuscular and oral administrations to normal subjects. J. Pharm. Sci. 73:1108-1113 (1984).

18. J. G. Wagner. Estimation of theophylline absorption rate by means of the Wagner-Nelson equation. J. Allergy Clin. Immunol. 78 (Part 2):681-688 (1986).

19. J. G. Wagner. Inter- and intrasubject variation of digoxin renal clearance in normal adult males. Drug Int. Clin. Pharm. 22:562-567 (1988).

20. J. G. Wagner, P. D. Holmes, P. K. Wilkinson, D. C. Blair, and R. G. Stoll. Importance of the type of dosage form and saturable acetylation in determination the bioavailability of p-aminosalicylic acid. Am. Rev. Resp. Dis. 108:536-546 (1973).

21. K. S. Albert, E. Sakmar, M. R. Hallmark, D. J. Weidler, and J. G. Wagner. Bioavailability of diphenylhydantoin. Clin. Pharmacol. Ther. 16:727-735 (1974).

22. K. S. AJbert, A. J. Sedman, and J. G. Wagner. Pharmacokinetics of orally administered acetaminophen in man. J. Pharmacokin. Biopharm. 2:381-393 (1974).

23. T. J. Sullivan, E. Sakmar, K. S. Albert, D. C. Blair, and J. G. Wagner. In vitro and in vivo availability of commercial prednisone tablets. J. Pharm. Sci. 64:1723-1725 (1975).

24. T. J. Sullivan, M. R. Hallmark, E. Sakmar, D. J. Weidler, R. H. Earhart, and J. G. Wagner. Comparative bioavailability: Eight commercial prednisone tablets. J. Pharmacokin. Biopharm. 4:157-172 (1976). 
25. A. V. Tembo, M. R. Hallmark, E. Sakmar, H. G. Bachmann, D. J. Weidler, and J. G. Wagner. Bioavailability of prednisolone tablets. J. Pharmacokin. Biopharm. 5:257-270 (1977).

26. J. W. Ayres, D. J. Weidler, J. MacKichan, E. Sakmar, M. R. Hallmark, E. F. Lemanowicz, and J. G. Wagner. Pharmacokinetics of tolmetin with and without concomitant administration of antacid in man. Eur. J. Clin. Pharmacol. 12:421-428 (1977).

27. R. F. Bergstrom, D. R. Kay, T. M. Harcom, and J. G. Wagner. Penicillamine kinetics in normal subjects. Clin. Pharmacol. Ther. 30:404 413 (1981).

28. G. F. Lockwood, K. S. Albert, W. R. Gillespie, G. G. Bole, T. M. Harkcom, G. J. Szpunar, and J. G. Wagner. Pharmacokinetics of ibuprofen in man: I. Free and total area/dose relationships. Clin. Pharmacol. Ther. 34:97-103 (1983).

29. G. J. Szpunar, K. S. Albert, G. G. Bole, J. N. Dreyfuss, G. F. Lockwood, and J. G. Wagner. Pharmacokinetics of flurbiprofen in man. I. Area/dose relationship. Biopharm. Drug Dispos. 8:273-283 (1987).

30. MINSQ and RSTRIP, MicroMath Scientific Software, P.O. Box 21550, Salt Lake City, UT 84121 .

31. K. Yamaoka, T. Nakagawa, and T. Uno. Statistical moments in pharmacokinetics. $J$. Pharmacokin. Biopharm. 6:547-558 (1978).

32. J. G. Wagner. Types of mean residence times. Biopharm. Drug Dispos. 9:41-57 (1988).

33. P. Veng-Pedersen. Linear and nonlinear system approaches in pharmacokinetics: How much do they have to offer? I. General considerations. J. Pharmacokin. Biopharm. 16:413472 (1988).

34. D. A. Ganes. Metabolic and pharmacokinetic studies of thioridazine, mesoridazine and sulforidazine in the dog and man. Ph.D. thesis, College of Pharmacy, University of Saskatchewan, Saskatoon, Saskatchewan, Canada, 1987, p. 345.

35. I. Gonzalez. Absorption of flurbiprofen and some other drugs through oral mucosa. Ph.D. thesis, College of Pharmacy, The University of Michigan, Ann Arbor, Michigan, 1989, p. 271.

36. G. J. Szpunar. The pharmacokinetics of flurbiprofen in man. Ph.D thesis, College of Pharmacy, The University of Michigan, Ann Arbor, Michigan, 1984, p. 248.

37. I. M. Kapetanovic, C. D. Torchin, H. J. Kupferberg, D. M. Treiman, C. DiGiorgio, K. Barber, L. Norton, M. Lau, L. Whitley, and J. J. Cereghino. Pharmacokinetic profile of flunarizine after single and multiple dosing in epileptic patients receiving comedication. Epilepsia 29:770-774 (1988).

38. S. A. Kaplan, M. L. Jack, K. Alexander, and R. E. Weinfeld. Pharmacokinetic profile of diazepam in man following single intravenous and oral and chronic oral administrations. J. Pharm. Sci. 62:1789-1796 (1973).

39. P. Veng-Pedersen. Linear and nonlinear system approaches in pharmacokinetics: How much do they have to offer? II. The response mapping operator (RMO) approach. $J$. Pharmacokin. Biopharm. 16:543-571 (1988).

40. P. Veng-Pedersen. System approaches in pharmacokinetic: I. Basic concepts. J. Clin. Pharmacol. 28:1-5 (1988).

41. P. Veng-Pedersen. System approaches in pharmacokinetics: II. Applications. J. Clin. Pharmacol. 28:97-104 (1988).

42. J. M. van Rossum and J. E. G. M. de Bie. System dynamics in clinical pharmacokinetics: An introduction. Clin. Pharmacokin. 17:27-44 (1989).

43. J. M. van Rossum, J. E. G. M. de Bie, G. van Lingen, and H. W. A Teeuwen. Pharmacokinetics from a dynamical systems point of view. J. Pharmacokin. Biopharm. 17:365-392 (1989).

44. J. G. Wagner. Linear pharmacokinetic models and vanishing exponential terms: Implications in pharmacokinetics. J. Pharmacokin. Biopharm. 4:395-425 (1976).

45. N. Watari and L. Z. Benet. Determination of mean input time, mean residence time, and steady-state volume of distribution with multiple drug inputs. J. Pharmacokin. Biopharm. 17:593-599 (1989). 